\title{
Evaluation of a neighbourhood scale, street network dispersion model through comparison with wind tunnel data
}

\author{
Matteo Carpentieri \\ Pietro Salizzoni \\ Alan Robins \\ Lionel Soulhac
}

Environmental Modelling and Software 37, 110-124 [2012]

doi: $10.1016 /$ j.envsoft.2012.03.009

\begin{abstract}
This study compared dispersion calculations using a street network model (SIRANE) with results from wind tunnel experiments in order to examine model performance in simulating short-range pollutant dispersion in urban areas. The comparison was performed using a range of methodologies, from simple graphical comparisons (e.g. scatter plots) to more advanced statistical analyses. A preliminary analysis focussed on the sensitivity of the model to source position, receptor location, wind direction, plume spread parameterisation and site aerodynamic parameters. Sensitivity to wind direction was shown to be by far the most significant. A more systematic approach was then adopted, analysing the behaviour of the model in response to three elements: wind direction, source position and small changes in geometry. These are three very critical aspects of fine scale urban dispersion modelling. The overall model performance, measured using the Chang \& Hanna (2004) criteria can be considered as 'good'. Detailed analysis of the results showed that ground level sources were better represented by the model than roof level sources. Performance was generally 'good' for wind directions that were very approximately diagonal to the street axes, while cases with wind directions almost parallel (within $20^{\circ}$ ) to street axes gave results with larger uncertainties (failing to meet the quality targets). The methodology used in this evaluation exercise, relying on systematic wind tunnel studies on a scaled model of a real neighbourhood, proved very useful for assessing strengths and weaknesses of the SIRANE model, complementing previous validation studies performed with either on-site measurements or wind tunnel measurements over idealised urban geometries.
\end{abstract}

\section{Introduction}

Operational dispersion models are commonly used to determine the exposure of the population to pollutants in urban areas and to help develop strategies for its reduction. This requires mapping of pollutant concentrations throughout an area of interest, generally in terms of both time and spatial scales. Atmospheric dispersion models are essential for 
that purpose because the data provided by monitoring stations cannot provide a sufficiently detailed coverage (Ball et al., 2008; Scaperdas and Colvile, 1999). The temporal and spatial details to which dispersion models must extend depends on their purpose and application. Traditionally (Oke, 1987), the scale of atmospheric motions and related phenomena have been classified according to their horizontal scale into four broad categories: macroscale, mesoscale, local scale and microscale. Britter and Hanna (2003) interpret these as 'regional' scale (up to 100 or $200 \mathrm{~km}$ ), 'urban' (city) scale (up to 10 or $20 \mathrm{~km}$ ), 'neighbourhood' scale (up to 1 or $2 \mathrm{~km}$ ) and 'local' (street) scale (less than 100-200 m). These horizontal scales are strongly linked to corresponding vertical and temporal scales.

Britter and Hanna (2003) argue that the neighbourhood scale is a spatial scale over which some statistical homogeneity can be anticipated and thus general parameterisations of the flow can be attempted. It is also a scale at which detailed computational study is feasible with the required high resolution implied in this form of investigation. Many recent urban modelling development efforts have concentrated on the neighbourhood scale (see, e.g., Belcher, 2005; Hamlyn et al., 2007; Di Sabatino et al., 2008). Dispersion models at this particular scale must be able to deal with the mechanisms that determine pollutant transport within and above the urban canopy (Britter and Hanna, 2003). These are complex and chiefly related to the channelling effect due to advective transport along streets, vertical mass exchanges between street canyons and the overlying atmosphere and pollutant transfer at street intersections (Carpentieri et al., 2009; Carpentieri and Robins, 2010). Current 'operational models' describe these processes to some degree or another by means of parametric relations.

Standard methods for predicting urban air pollution, resulting primarily from emissions from traffic, have been reviewed by Vardoulakis et al. (2003). The street canyon model described by Berkowicz (2000) is one of the well-established, standard models for this purpose. Like all operational models, it uses a simplified description of flow and dispersion conditions in street canyons, in this case based on a box model that treats pollutant recirculation and exchange with the external flow, and a plume model that describes the direct advection of pollutant from source to receptors within a street canyon. OSPM (Operational Street Pollution Model), an operational version of the model, has been extensively tested against observations (e.g. Kukkonen et al., 2003). The same approach is used in ADMS-Urban where, again, it has been extensively tested against observations (e.g. CERC, 2001). OSPM and its derivatives can be regarded as mature systems with a performance that is now firmly established. Their strength is in predicting exposure to pollution from traffic flows when the sources and receptors are in the same street canyon. It does not though treat the exchange of pollutants between streets at intersections, other than in a very general sense through the background concentration field.

Models that are to handle the dispersion of hazardous material from point-like sources in urban areas must represent not only dispersion within a street canyon and mixing with the external flow but also exchanges at intersections, as contaminated air works its way through a street network (Hunt et al., 2004). The basic street canyon model needs some additional capabilities to enable this. An alternative approach is based on treating urban areas as a canopy, through which the flow is determined by a balance between the driving shear force from above and the drag within the canopy. This is the basis for models such 
as UDM, Urban Dispersion Model, (Hall et al., 2001; Brook et al., 2003) and the socalled Baseline Urban Dispersion Model (Hanna et al., 2003). In the latter, dispersion is treated through simple modifications to standard plume spread relationships whereas in the former a more complex approach is adopted based on statistical relationships between dispersion and the geometrical characteristics of the urban area, together with explicit treatment of plume partitioning by interactions with large buildings (i.e. large relative to the plume). These models have been extensively tested against field and wind tunnel data and their limitations understood.

Street network models, of which SIRANE (Soulhac et al., 2011) is the prime example, are relatively new and consequently their strengths and weaknesses less well understood. They are box models at heart but formulated with explicit modelling of the exchange of flow and pollutant fluxes at urban intersections and capable of providing a detailed concentration field at the street scale over a whole urban district. SIRANE was developed at the Laboratoire de Mecanique des Fluides et d'Acoustique (LMFA) de l'Ecole Centrale de Lyon. In this work, we are interested in evaluating how this class of 'street network' model performs in a real geometry, and in the sensitivity of its performance to input data and application.

For model evaluation purposes, there are many collections of good quality data from urban dispersion experiments, from field - e.g. Salt Lake City (Allwine et al., 2002); London (Wood et al., 2009) - and wind tunnel work (e.g. the CEDVAL data-base at the University of Hamburg). A first evaluation of the performance against a field dataset collected in a district of Lyon, has been already performed and is reported elsewhere (e.g. Soulhac et al., 2003, 2012). The sensitivity analysis showed that the model outputs were mainly sensitive to errors in two input parameters: the intensity of pollutant sources and the wind velocity. In the present work, the uncertainties related to both inputs are minimised, since the reference dataset refers to wind tunnel experiments, with a fully controlled environment with steady and fully defined boundary conditions. This allows us to focus on the influence of uncertainties arising from other input parameters, which would be difficult to analyse in field experiments. This is the case, for example, for local changes in the geometry of the street network, that are easy to do in small-scale urban models. Furthermore, this allows us also to test some of the parameterisations implemented in the model, such as those related to pollutant dispersion in the wind field above the urban canopy. Tests of the parameterisation for the pollutant transfer within the canopy have already been the object of a previous study (Garbero, 2008) that was performed by reducing as far as possible the irregularities of the urban geometry on a physical domain that was as close as possible to the conceptualisation of the modelled system (see Figure 1a).

In comparison with the methodology developed by Jakeman et al. (2006) and applied, e.g., by Blocken and Gualtieri (2012) for CFD (Computational Fluid Dynamics) environmental models, the evaluation presented here covers part of the objectives included in the last two steps of the development and evaluation of an environmental model. The results presented here, complemented by those of other validations and analyses (e.g. Soulhac et al., 2003; Garbero, 2008; Soulhac et al., 2012), provide the essential information needed to understand and explain the limitations of the model performance in realistic urban settings. A further step can now be contemplated, return to and revise the definition of the parametric laws adopted by the model. The new version then has 
to be tested against experimental data, giving rise to an iterative evaluation process for the improvement of the overall model performances.

For critical examination of model performance we need an exhaustive data-base that can be used to investigate effects of wind direction, source location and receptor location, implying a degree of systematic variation in those parameters. Ideally, the geometry should be relatively easy to define so that it can be simulated in the model without need of any significant simplification. Finally, a sufficiently large set of data is required to ensure statistical confidence in the results. Wind tunnel work undertaken in the Environmental Flow Research Centre (EnFlo) at the University of Surrey as part of the DAPPLE project (Dispersion of Air Pollutants and their Penetration into the Local Environment; Arnold et al., 2004; Wood et al., 2009) provides data that meet these requirements and has therefore been used for the model evaluation. The data and final reports from the project are freely available from www.dapple.org.uk.

The statistical indices proposed by Chang and Hanna (2004) are very widely applied to evaluating the performance of atmospheric dispersion models. Four of the indices are used here, the fractional bias, the normalised mean square error, the correlation coefficient and the fraction of predictions within a factor of two of the observations. Chang and Hanna (2004) define a 'good' model in terms of numerical ranges for these parameters. We adopt that procedure here and use the description 'a good model' in this formal sense. We also use scatter plots of predicted and observed concentrations and decay plots showing how concentrations decay away from a source to shed further light on model performance.

Section 2 provides a brief review of the basis of the SIRANE model, Section 3 the wind tunnel work and Section 4 the model set-up. Two sub-sets of the full DAPPLE data-base are used, the first to examine overall features of model performance (Section 5 ) and the second to study response to a range of systematic variations in the boundary conditions (Section 6). Section 7 summarises the overall outcome of the study.

\section{The SIRANE model}

SIRANE is a model for transport and dispersion of pollutants in urban areas (Soulhac et al., 2011). The streets in a city district are represented as a network of connected street canyon segments (Figure $1 \mathrm{~A}$ ) and the overlying boundary layer flow is modelled by MoninObukhov similarity theory. The outputs of the model are concentrations in the external flow, referred to as $C_{\text {ext }}$, and spatially averaged concentrations within each street segment, referred to as $C_{\text {street }}$.

The flow within each street canyon segment is driven by the component of the turbulent shear force in the external flow that is parallel to the street (Soulhac et al., 2008), and the pollutant is assumed to be uniformly mixed within the street segment. The model contains three main mechanisms for transport within the urban canopy:

- turbulent transfer across the interface (Figure 1 b) between the air in the street and the overlying boundary layer (Salizzoni et al., 2009a);

- the advective fluxes along the street axes which produce the channeling of pollutant along directions not generally parallel to the external wind direction (Soulhac et al., 2009); 
- the turbulent fluxes at the street intersection which are responsible for the spread of pollutant within the canopy (Figure 1 $\mathrm{k}$ ).

The turbulent flux at the interface between the street segment and the boundary layer above, referred to as $Q_{H, t u r b}$, is modelled by a standard concentration gradient approach, written in terms of a transfer velocity as

$$
Q_{H, t u r b}=u_{d} W L\left(C_{\text {street }}-C_{\text {ext }}\right)
$$

where $W$ and $L$ are the street width and length respectively; $u_{d}$ is a mixing, or transfer velocity defined as

$$
u_{d}=\frac{\sigma_{w}}{\sqrt{2 \pi}}
$$

where $\sigma_{w}$ is the standard deviation of the vertical component of the turbulent velocity and estimated by means of similarity relations as a function of the external boundary layer conditions (i.e. the friction velocity and Monin-Obukhov length), according to MoninObukhov similarity theory.

The flow and pollutant exchanges at street canyon intersections result from the advection of pollutant along streets feeding an intersection and their redistribution among the downwind streets. The mean advective flux of pollutant at the downwind section of a street segment is computed as

$$
C_{\text {street }} U_{\text {street }} H W
$$

where $C_{\text {street }}$ is the time and space averaged concentration within the street, $U_{\text {street }}$ is the time and space averaged wind velocity along the street axis, and $H$ and $W$ are the street height and width, respectively.

The exchange process within an intersection is simulated by an empirically based algorithm (Soulhac et al., 2009) that computes the partition of the mass fluxes along the street segments as a function of the geometry of the intersection, the external wind direction and $\sigma_{\phi}$, the standard deviation of the external wind direction fluctuations. The parameter $\sigma_{\phi}$ is estimated by similarity relations as a function on the external boundary layer conditions. Any imbalance results in a vertical exchange with the overlying boundary layer flow.

The dispersion of pollutants advected or diffused into the overlying boundary layer flow is treated by a Gaussian plume model (Figure 1 d). The growth of the plume spread scales, the standard deviations $\sigma_{y}$ and $\sigma_{z}$, with fetch depends on the intensity of atmospheric turbulence and consequently on thermal stratification in the atmosphere. SIRANE includes two options for treating these terms. The first is based on the well-known Pasquill-Gifford stability classes (Briggs, 1973; Pasquill and Smith, 1983) and referred to as the "Briggs" parameterisation in the following sections. The second is a continuous parameterisation using Monin-Obukhov similarity theory, based on the approaches proposed by Weil (1985), Venkatram (1992) and CERC (2001). It is referred to as "Monin-Obukhov" parameterisation.

In general, pollutant may reach a downwind receptor by the combined effects of advection through the street network and transport above roof level coupled to downward diffusion into street canyons. One route may dominate in any particular case. In the near-field, the exchange with the boundary layer above roof level is primarily a loss 

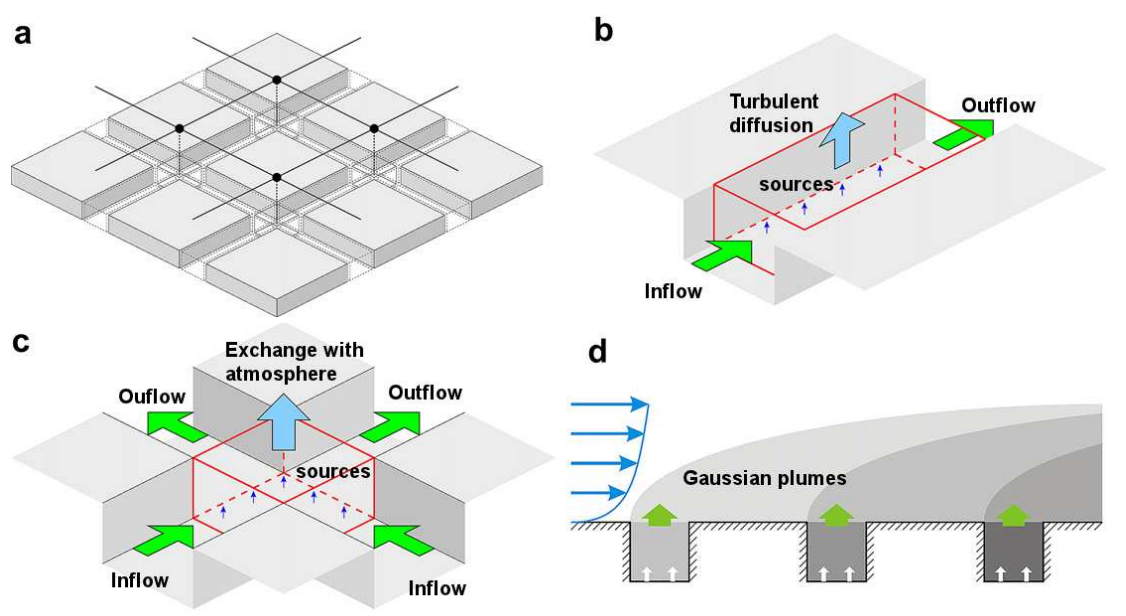

Figure 1: The main components of SIRANE: (a) a model of a district as a network of streets; (b) a box model for each street segment, with corresponding flux balances; (c) fluxes at a street intersection; (d) a modified Gaussian plume for dispersion in the external boundary layer

mechanism for pollutant in a street segment. It is further downwind that this can change to a gain, something that arises naturally because concentrations in a street segment become smaller that those in the flow above roof level. Boundary layer dispersion eventually dominates far downwind, where the plume becomes very deep relative to the underlying buildings. At this stage, the concentrations in the streets are derived directly from those in the concentration field above roof level.

The input data required by the model are the external wind speed and direction, the surface roughness length and displacement height characterising the district (see Section 4), the atmospheric stability and the emissions within each street segment in the network, together with the geometry as a network of connected streets.

An important limitation of the model is that it provides only the averaged value of pollutant concentrations within the volume of each street canyon segment and assumes that the wind field above roof level is horizontally uniform. The main geometrical limitations are that SIRANE does not currently distinguish between streets partially bordered by buildings (i.e. on one side only) and streets not bounded on both sides, and there is no specific model for pollutant transfer within large urban squares, which are designated as open terrain regions. Because of these constraints, the model applies more to districts with high building density and is likely to be less accurate when applied to districts with low building density. The reader is referred to Soulhac et al. (2011) for a detailed description of the parameterisations incorporated in the model.

\section{Experimental details}

The passive scalar dispersion experiments were performed in the EnFlo Laboratory using a 1:200 scale physical model of the urban area centred on the intersection between Marylebone Road and Gloucester Place in central London (Figure 2). Each street building block in the 'base' model was simply represented by a sharp edged block with a flat roof. A 


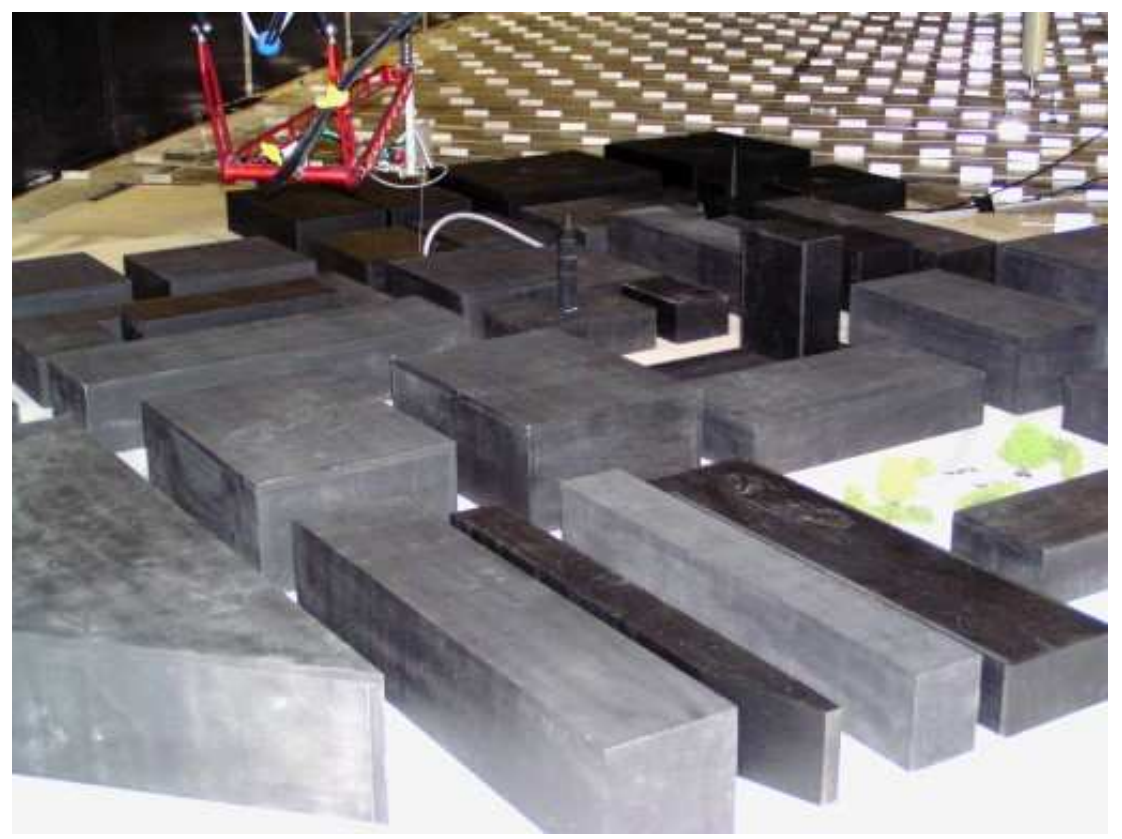

Figure 2: The model installed in the wind tunnel

plan of the model is given as Figure 3 and this includes the definition of the co-ordinate system. Wind directions are measured from the $x$-axis, positive anticlockwise.

The approach flow was a $1 \mathrm{~m}$ deep boundary layer, simulating a $200 \mathrm{~m}$ deep atmospheric boundary layer in neutral conditions. Standard Irwin vorticity generators (Irwin, 1981) were installed at the entrance to the test section and roughness elements on the tunnel floor to create the required boundary layer conditions. The roughness elements were $80 \mathrm{~mm}$ wide and $20 \mathrm{~mm}$ tall vertical flat plates placed normal to the flow, arranged in a staggered pattern between rows with a lateral and longitudinal spacing of $240 \mathrm{~mm}$ (see Figure 2). An ultrasonic anemometer, fixed at $1 \mathrm{~m}$ above the tunnel floor and approximately $11 \mathrm{~m}$ downstream of the working section inlet, was used to measure the reference velocity in the free stream, $U_{r e f}$.

The mean velocity profile in the approach flow upstream of the model can be accurately described by a standard logarithmic profile:

$$
U(z)=\frac{u^{*}}{k} \ln \left(\frac{z-d}{z_{0}}\right)
$$

with:

$$
\frac{z_{0}}{\delta}=0.0014, \quad d=0, \quad \frac{u^{*}}{U_{\text {ref }}}=0.054
$$

where $k$ is the Von Karman's constant (taken as 0.41 ), $z_{0}$ the surface roughness length, $\delta$ the boundary layer depth, $d$ the zero plane displacement, $u^{*}$ the friction velocity and $U_{r e f}$ the wind speed at height $\delta$ (the free stream velocity). The wind speed at roof level in the approach flow is: $U_{h}=0.59 U_{\text {ref }}$. Here, 'roof level' is defined as the mean building height of the model, which is $h=110 \mathrm{~mm}$ (model scale) or $22 \mathrm{~m}$ (full scale). The simulations were carried out with $U_{\text {ref }}=2.5 \mathrm{~m} \mathrm{~s}^{-1}$, giving a Reynolds number (Re) based on $h$ and $U_{h}$ of $1.1 \cdot 10^{4}$, which satisfies the critical condition for Reynolds number independence (Snyder, 1981). 


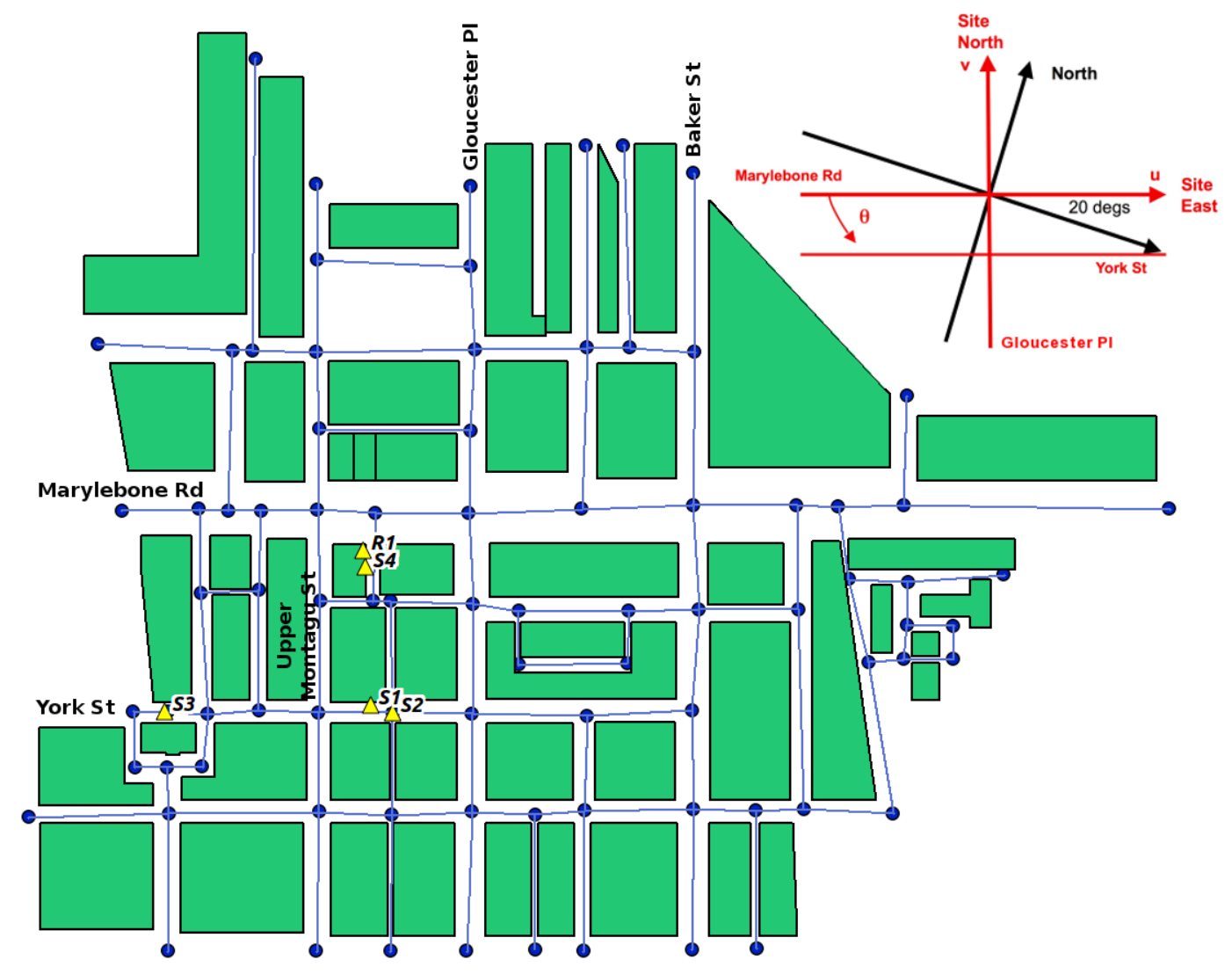

Figure 3: Plan of the DAPPLE model showing the street network used with SIRANE (nodes and street segments, represented, respectively, as dots and lines), source positions and reference system. The site reference system is rotated by $20^{\circ}$ anticlockwise with respect to the geographical reference system (see top-right in the Figure). Source positions used in the first set of experiments are also marked (S1 to S4, street level, and R1, roof level) 
An ethane-air mixture was emitted continuously from point sources placed at different locations both at ground and roof level, the ethane acting as the tracer gas. Source positions are described in the following sections, as required by the particular cases presented. Tests in which either the emission rate or the reference velocity were varied confirmed that the emission could be treated as passive. Tracer concentrations were measured with a Fast response Flame Ionisation Detector (FFID). Concentrations were averaged over a time sufficient to provide reliable statistics, generally over $3 \mathrm{~min}$, except the final experiments (see Section [6.3), where a 5-min averaging time was used.

\section{Model set-up and simulation scenarios}

SIRANE uses data from a "meteorological site" to define reference wind conditions (and other meteorological inputs). The upper level wind is then calculated and used together with surface conditions over the urban area to derive a local wind profile. The wind tunnel approach flow conditions, upwind of the DAPPLE model, provided the meteorological site data, set as: $z_{0, a}=0.28 \mathrm{~m}, d_{a}=0, U_{h}=1.5 \mathrm{~m} \mathrm{~s}^{-1}, h=22 \mathrm{~m}$. The value assigned to $U_{h}$ was arbitrary as neutral conditions were imposed and all results analysed in dimensionless form, as described in Section 5.1, and therefore independent of the value of $U_{h}$.

The aerodynamic properties (roughness length and zero plane displacement) of the modelled urban area (the "urban site"), referred to as, respectively, $z_{0, m}$ and $d_{m}$, were estimated by using the morphological technique developed by Macdonald et al. (1998). The mean building height, $h=22 \mathrm{~m}$, the plan area index $\lambda_{p}=0.54$ and the frontal area indexes $\lambda_{f}=0.16$ to 0.28 (depending on the wind direction) were used as input parameters to calculate $z_{0, m}$ and $d_{m}$.

The model evaluation study was performed in two phases, using different reference datasets. The first included experiments performed with a range of source locations (both within the street canyons and at roof level), wind directions and receptor locations. This study addressed overall model performance for both ground level and roof level sources. The second set of data included a more extensive series of wind tunnel results in which the experimental parameters were varied systematically. This tested the sensitivity of the model to changes in wind direction, source location and local modifications to the street network geometry.

\section{$5 \quad$ Evaluation phase 1}

Five cases were selected to cover a range of wind directions and source locations, as summarised in Table 1. These test cases were originally designed to simulate five field experiments carried out on-site in 2003 and 2004 (Wood et al., 2009). Wind directions are defined in the site-aligned system reported in Section 3 and in Figure 3 , which also shows the source locations. Two field experiments were run at the same time in Cases 2 , 3 and 4 by releasing different tracers from the two sources. These were run separately in the wind tunnel, so in total there are eight dispersion experiments to be modelled. The full dataset comprised 69 measurements.

Simulations with SIRANE used continuous releases of pollutants from point sources at ground and roof level. Simulations were carried out using the boundary layer dispersion 
Table 1: The Phase 1 dataset, based on 2003 and 2004 field trials; source positions are marked in Figure 3. Wind directions are expressed in the site co-ordinate system and $U_{h}$ is the wind speed measured at roof level in the field

\begin{tabular}{cccc}
\hline Case No. & Source & $U_{h}[\mathrm{~m} / \mathrm{s}]$ & Wind direction $\left[^{\circ}\right]$ \\
\hline 1 & S1 & 3.0 & 51 \\
2 & S2, S3 & 2.0 & 33 \\
3 & S2, R1 & 2.5 & 45 \\
4 & S4, R1 & 1.9 & 106 \\
5 & R1 & 1.7 & -97
\end{tabular}

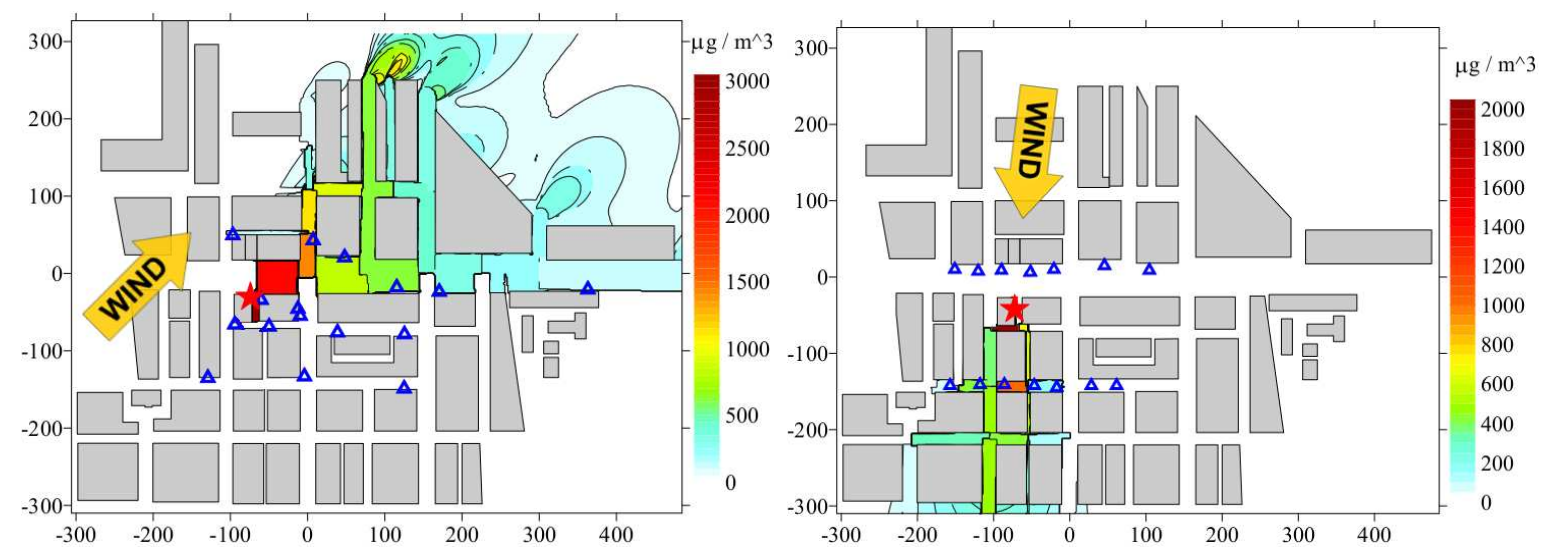

Figure 4: Ground level concentration maps: Case 3-R1 (left) and Case 5 (right); blue triangles represent receptor positions, while red stars are the emission sources used in the field

model based on Monin-Obukhov similarity theory because of its more accurate description of the physical processes than the "Briggs" approach. The aerodynamic parameters of the urban site were $d_{m}=17 \mathrm{~m}, z_{0, m}=0.5 \mathrm{~m}$ (for Cases 1,2 and 3 ) and $z_{0, m}=0.4 \mathrm{~m}$ (for Cases 4 and 5). Example results from the SIRANE simulations are shown in Figure 4. As expected of a box model, this shows constant concentrations in each street segment, with plume-like structures developing downwind of the model. Large concentration gradients are apparent at some intersections, reflecting the pollutant exchanges between the streets.

\subsection{Comparison with wind tunnel data}

Results from the SIRANE calculations are compared with the wind tunnel measurements in terms of the dimensionless concentration, $C^{*}$ :

$$
C^{*}=\frac{C U_{h} h^{2}}{Q}
$$

where $C$ is the volume concentration, $U_{h}$ the roof level wind speed, $h$ the mean building height and $Q$ the volumetric flow rate from the source. The first stage in the comparison was a simple graphical evaluation through the scatter plots presented in Figure 5, for the full dataset, and Figure 6 for ground level and roof level sources separately. 


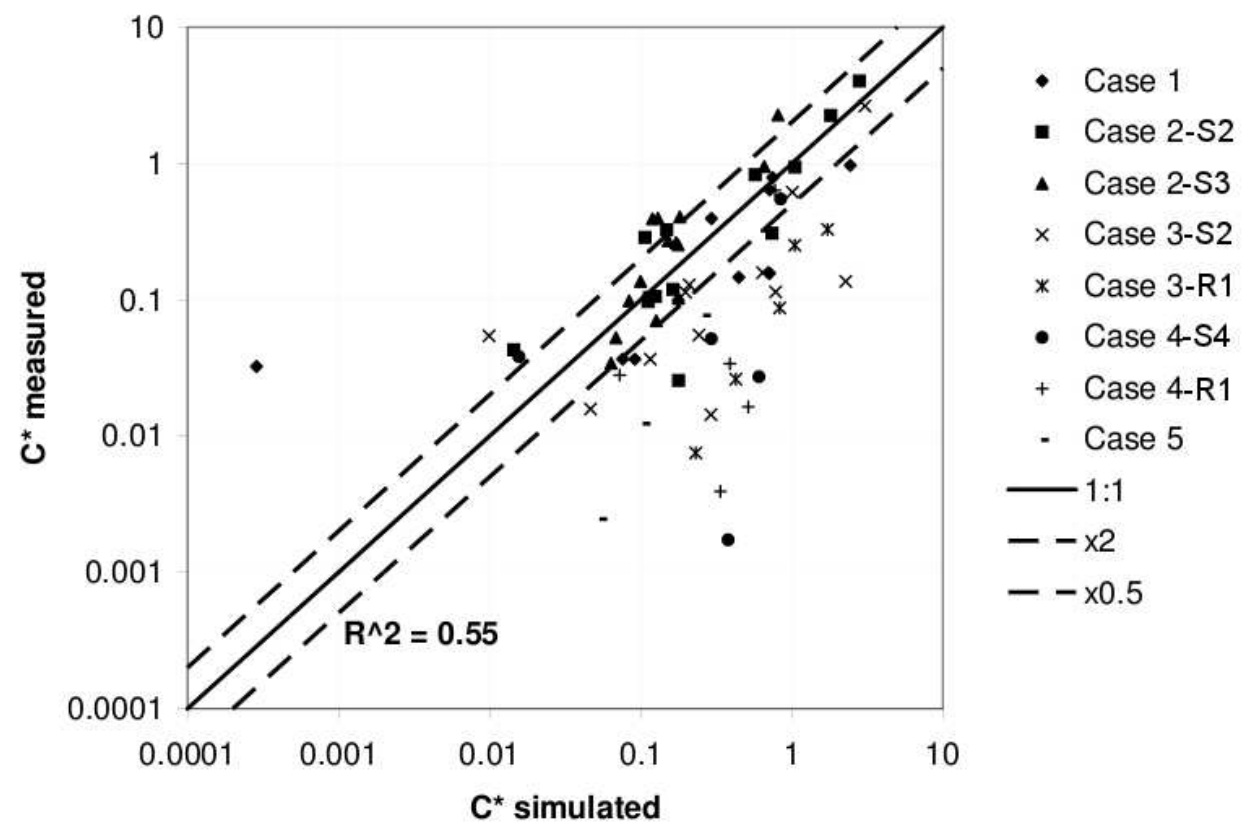

Figure 5: Scatter plot comparing wind tunnel data and numerical results for the base case simulations; $R^{2}$ is the coefficient of determination; 69 data points. The solid line indicates $1: 1$ correspondence and the dashed lines $1: 2$ and $2: 1$
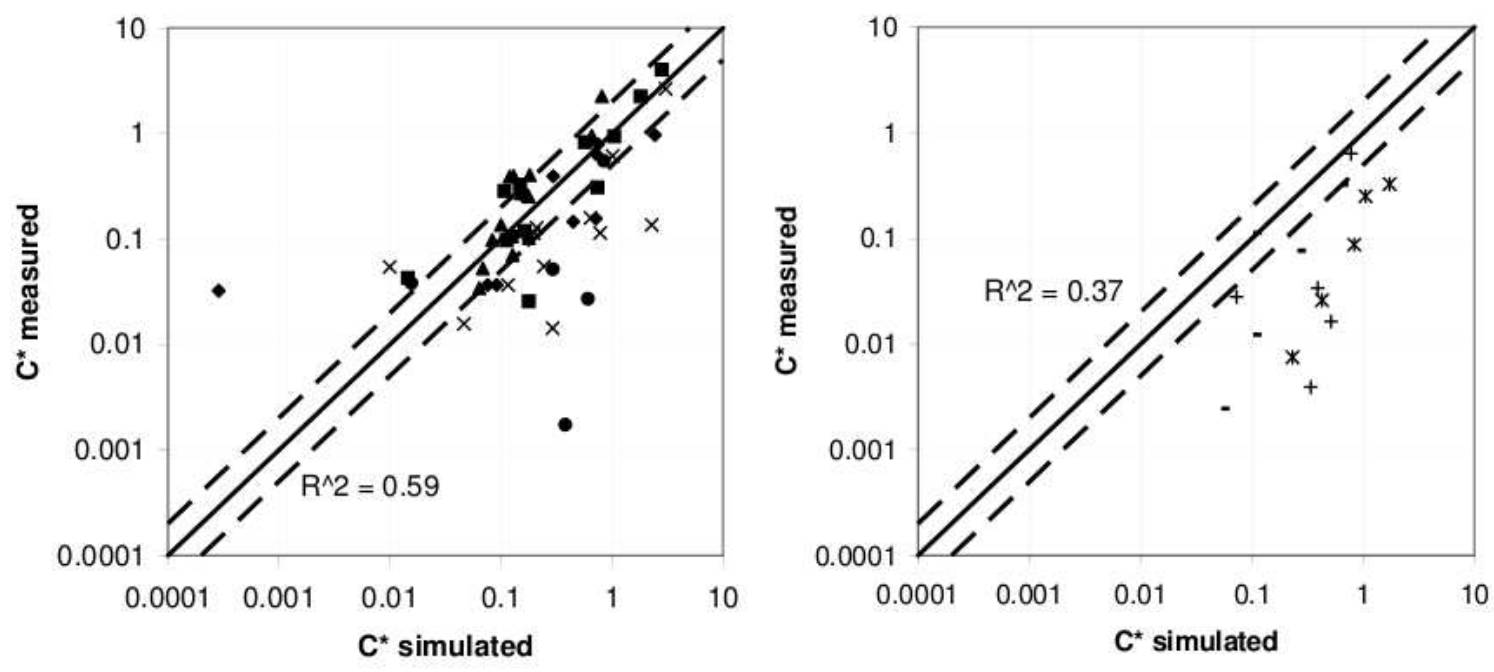

Figure 6: Scatter plot comparing wind tunnel data and numerical results for ground level sources (left, 53 data points) and roof level sources (right, 16 data points); see legend in Figure 5 
Table 2: Statistical evaluation of SIRANE predictions for the Phase 1 experiments

\begin{tabular}{ccccc}
\hline Ideal target $->$ & 0 & 0 & 1 & 1 \\
\hline 'Good' (Chang\&Hanna 2004) $->$ & abs $\leq 0.3$ & $\leq 4$ & - & $\geq 0.5$ \\
\hline Data set & FB & NMSE & R & FAC2 \\
\hline All data / Monin-Obukhov & -0.33 & 1.35 & 0.74 & 0.43 \\
Ground level sources (MO) & -0.18 & 1.12 & 0.77 & 0.49 \\
Roof level sources (MO) & -1.18 & 4.12 & 0.61 & 0.20 \\
\hline
\end{tabular}

The second step of the comparison was a statistical evaluation of model performance. Four of the statistical indices proposed by Chang and Hanna (2004) have been used as these are sufficient to reveal the important features of the evaluation exercise. These are:

- the fractional bias $(\mathrm{FB}): \overline{\left(X_{O}-X_{P}\right)} / 0.5 \overline{\left(X_{O}+X_{P}\right)}$;

- the normalised mean square error (NMSE): $\overline{\left(X_{O}-X_{P}\right)^{2}} /\left(\bar{X}_{O} \bar{X}_{P}\right)$;

- the correlation coefficient $(\mathrm{R})$;

- the fraction of predictions within a factor of two of the observations (FAC2);

where $X$ is a generic variable, the suffix ' $\mathrm{O}$ ' denotes an observation and ' $\mathrm{P}$ ' a prediction.

The results are summarised in Table 2, which includes the three targets for a 'good' model defined by Chang and Hanna (2004). Overall model performance meets the NMSE target and narrowly falls short of the other two. Performance for ground level sources is clearly better than for roof level sources, though it should be noted that there are significantly fewer observations in the latter case (16 as opposed to 53). The model shows a general tendency to overestimate the wind tunnel measurements (negative values of FB) which is more evident in the case of the roof level sources. This fact suggests that the model tends to underestimate the turbulent diffusivity in the lowest part of the boundary layer, usually referred to as the roughness sub-layer (RSL), where flow and dispersion are directly influenced by the wake of each building. In order to explain this it is worth mentioning that the turbulent diffusivity in the RSL is greater than that given by a simple linear increase in diffusivity with distance from the boundary, as in the inertial layer (Salizzoni et al., 2009b). In its present version, SIRANE does not take into account this increased diffusivity since it neglects the presence of the RSL and models the atmospheric boundary layer as an horizontally homogeneous flow extending down to roof level. This can be the reason of the overestimation of the ground level concentration by the model.

A similar analysis was then carried out with the experiments divided into two groups according to wind direction. This separated those cases where the wind was approximately parallel to streets (and normal to the others) from the remainder. For simplicity, we refer to the two as either 'normal' or 'diagonal'. Cases 4 and 5 were thus classified as normal and 1, 2 and 3 as diagonal (see Table 1). The analysis showed significantly worse performance for the 'normal' cases. The differences were sufficient to merit further investigation and this was included in Phase 2 of the evaluation study. 
Table 3: Statistical evaluation of SIRANE predictions for the Phase 1 experiments using the Briggs plume spread parameterisation

\begin{tabular}{|c|c|c|c|c|}
\hline Ideal target $->$ & 0 & 0 & 1 & 1 \\
\hline 'Good' (Chang\&Hanna 2004) -> & $\operatorname{abs} \leq 0.3$ & $\leq 4$ & - & $\geq 0.5$ \\
\hline Data set & FB & NMSE & $\mathbf{R}$ & FAC2 \\
\hline All data / Briggs & -0.07 & 1.32 & 0.78 & 0.49 \\
\hline Ground level sources (B) & -0.06 & 1.19 & 0.77 & 0.51 \\
\hline Roof level sources (B) & -0.15 & 0.69 & 0.77 & 0.40 \\
\hline
\end{tabular}

\subsection{Sensitivity analysis}

The next step in Phase 1 was to assess the sensitivity of the model to three main factors:

1. The parameterisation of plume spread in the boundary layer;

2. The values of the urban site aerodynamic parameters;

3. The wind direction of the external flow.

\subsubsection{Dispersion in the boundary layer}

Base case simulations presented in Section 5.1 were carried out using a dispersion model based on Monin-Obukhov similarity theory in the boundary layer above roof level. The simulations were repeated using the alternative and simpler Briggs approach, which is based on the Pasquill stability classes. The results of this comparison with the wind tunnel data and the differences relative to the base case are summarised in Table 3 .

In general, applying SIRANE with the Briggs parameterisation leads to improvement in some of the statistical indices, most notably to the fractional bias, FB. Changes to the other indices are much less significant, except for the roof level sources where considerable improvement is seen in all of them. Figure 7, the scatter plot, reinforces these comments when compared with the equivalent for the base case, Figure 5. The distribution of points is clearly more symmetrical around the 1:1 line, hence the improvement in FB, but the scatter is much the same (NMSE hardly changes for the complete set of data). The Briggs parameterisation assumes that plume spread is independent of height, using an averaged value throughout the boundary layer depth. This leads to higher diffusivity values in the lower part of the boundary layer than in the Monin-Obukhov case and therefore to generally smaller concentrations. Apparently, the higher diffusivity obtained by the Briggs parameterisation provides better modelling for the increased turbulent diffusivity in the RSL (see Section 5.1), which certainly plays a major role in short range pollutant transfer in urban areas. This can explain the improvement in the model performance with the Briggs parameterisation, even though this is certainly a simpler parametrisation than that provided by the Monin-Obukhov similarity theory.

\subsubsection{Aerodynamic parameters}

The estimation of the aerodynamic parameters characterising a group of obstacles is often subject to a large degree of uncertainty. For this reason we have tested the sensitivity of 


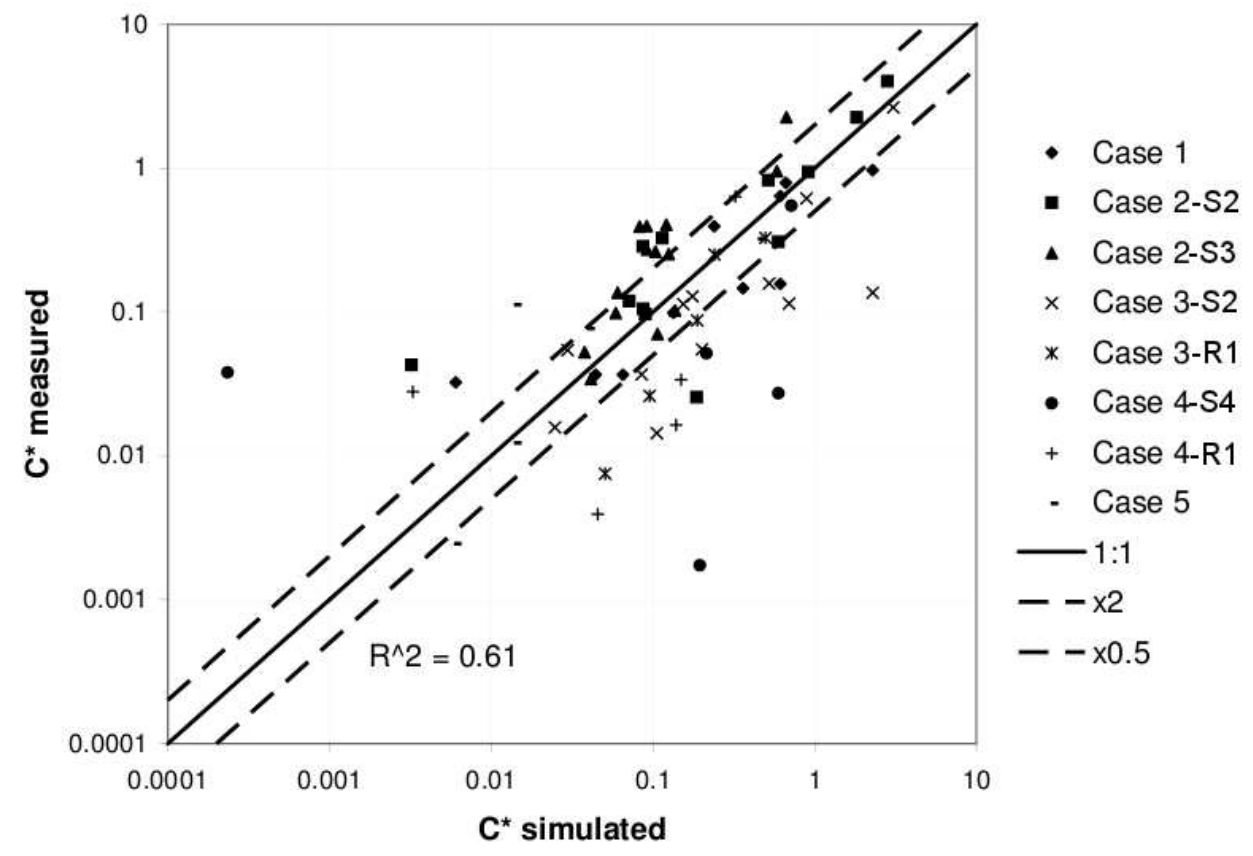

Figure 7: Scatter plot comparing wind tunnel data and numerical results using the Briggs plume spread parameterisation; $R^{2}$ is the coefficient of determination; 69 data points. The solid line indicates $1: 1$ correspondence and the dashed lines 1:2 and 2:1

the model performance to variations in both the site aerodynamic roughness, $z_{0, m}$, and the displacement height, $d_{m}$. These parameters have been varied by a modest amount around the reference values given in Section 4. The data at the meteorological site define the geostrophic wind speed and direction. These are then used with the urban site data to calculate the boundary layer conditions over the site; the friction velocity also determines the flow speeds in the street segments and the vertical turbulence intensity the transfer velocity (as in Equation 1). Thus the site aerodynamic parameters affect dispersion in both the street segments and the boundary layer.

Case 2 was chosen for this particular analysis and $z_{0, m}$ varied between $0.4 \mathrm{~m}$ and 1.1 $\mathrm{m}$, with $d_{m}$ independently varied between $13 \mathrm{~m}$ and $21 \mathrm{~m}$, ranges that were considered appropriate for the DAPPLE site. Results were analysed in terms of sensitivity ratios, these being the ratio of the fractional change in the output (in this case a statistical index) and the fractional change in the input parameter. Sensitivity ratios, $S R$, are defined as:

$$
S R=\left(\frac{I_{X V}-I_{X R}}{I_{X R}}\right) /\left(\frac{X_{V}-X_{R}}{X_{R}}\right)
$$

where $I$ denotes a statistical index, $X$ an input parameter and the suffices $V$ and $R$ the varied and reference conditions. A positive value of the ratio implies that the input parameter and output vary in the same sense (both positive or both negative); $S R=1$ indicates that the fractional change in the output is equal to the fractional change in the input.

As might be anticipated, the zero-plane displacement height had little influence on the calculated concentrations; e.g. for FB the mean value of $S R$ was 0.04 and the range 
Table 4: Sensitivity ratios for the wind direction, $\theta$ (T1: $\theta=40^{\circ}$, T2: $\theta=26^{\circ}$ )

\begin{tabular}{ccccc}
\hline & \multicolumn{2}{c}{ Case $2-S 2$} & \multicolumn{2}{c}{ Case $2-S 3$} \\
\hline Index & T1 & T2 & T1 & T2 \\
\hline FB & -1.28 & -1.57 & 1.71 & 1.54 \\
NMSE & -1.05 & -1.62 & 3.53 & 1.38 \\
R & 0.01 & 0.03 & -0.11 & 0.13 \\
FAC2 & 0.92 & 0.46 & -1.93 & 0.00 \\
\hline
\end{tabular}

from -0.07 to +0.21 . Slightly more significant changes were seen for variations in the roughness length. For FB the mean value of $S R$ was 0.23 and the range from +0.04 to +0.55 and for NMSE the mean was 0.24 and the range from +0.10 to +0.45 . Changes in the other two measures, $\mathrm{R}$ and FAC2, were negligible. From these results, given the general accuracy expected of dispersion modelling, we can assert that all that is necessary is that the urban site data for $d_{m}$ and $z_{0, m}$ fall within reasonable bounds.

The outcome that SIRANE is relatively insensitive to variations in the urban site aerodynamic parameters can be explained by recalling that pollutant exchanges within the urban canopy are mainly dependent on the value of the friction velocity over the canopy. The friction velocity is calculated from the boundary layer velocity profile, given the wind speed above the boundary layer (which is calculated from the meteorological station data). Small changes to $z_{0, m}$ and, in particular, $d_{m}$ have little influence on this calculation.

\subsubsection{Wind direction}

Finally, we tested the influence of variations in the wind direction, $\theta$, again using Case 2 as the reference. This parameter was varied by $\pm 7^{\circ}$ about the reference value of $\theta=33^{\circ}$. A slightly different approach has to be used with wind direction in forming the sensitivity ratio, with the fractional change in direction calculated relative to a $22.5^{\circ}$ wind direction 'sector'. Wind direction is often supplied in these terms, using 16 sectors, and $\pm 7^{\circ}$ relative to a sector centre, a fractional change of \pm 0.31 , is a sensible measure of the uncertainty in wind directions specified in this way. Results of the sensitivity analysis are listed Table 4 and show that the wind direction has a much greater impact than the other two parameters on the predictions. That wind direction is a critical input parameter is, of course, not unexpected.

\section{Evaluation phase 2}

The Phase 1 analysis showed that the performance of the model is strongly influenced by variations in the wind direction. In order to investigate this aspect further and analyse model performance, we used a series of wind tunnel experiments within the full DAPPLE data-base where the wind direction was varied systematically (with a step of $10^{\circ}$ ) and the source and receptor positions held fixed (see Section 6.1). Response to systematic changes in source position was then addressed (Section 6.2) using test cases for a single wind direction. Approximately 4000 measurements were available for the selected case, lending 


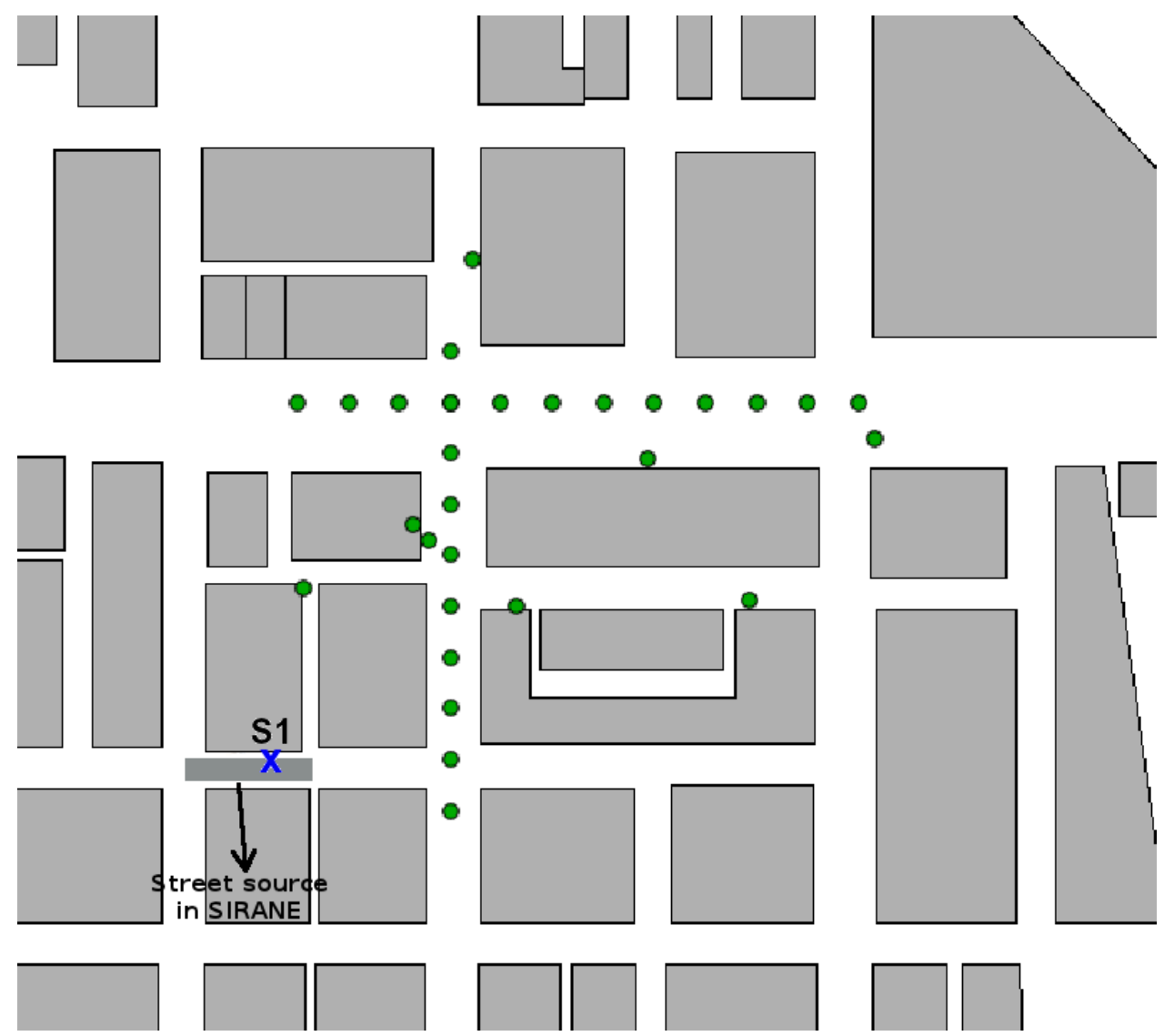

Figure 8: Source location ('x' symbol labelled S1 for the experiments, grey street segment for the simulations) and receptor positions (dots) used for studying the sensitivity to wind direction

particular strength to the statistical analysis of model performance in this particular situation. Finally, experiments in which selected streets were blocked were used to study the response of the model of local variations in the geometry of the urban district (Section 6.3).

The parameters for the meteorological site, defined by the neutrally stable approach flow in the wind tunnel, were: $z_{0, a}=0.28 \mathrm{~m}, d_{a}=0 \mathrm{~m}$ (at full scale). The roof level velocity $\left(U_{h}\right.$ at $\left.h=22 \mathrm{~m}\right)$ was used as the reference wind speed. Source conditions assumed a continuous release of pollutant from street level and the boundary layer dispersion model was based on Monin-Obukhov similarity theory, for the reasons explained in Section 5 .

\subsection{Response to wind direction changes}

The source location used for these test cases is marked as 'S1' in Figure8, which also shows the receptor locations. This source was simulated in SIRANE by applying a constant emission term within the corresponding street segment, shown shaded in the figure. Runs were undertaken for the following wind directions: $110^{\circ}, 100^{\circ}, 90^{\circ}, 80^{\circ}, 71.4^{\circ}, 61.4^{\circ}, 51.4^{\circ}$, $41.4^{\circ}, 31.4^{\circ}$, as in the experiments.

The full DAPPLE dataset showed very clearly that the maximum ground level concentration decayed as the inverse square of the separation, $s$, from the source. This 

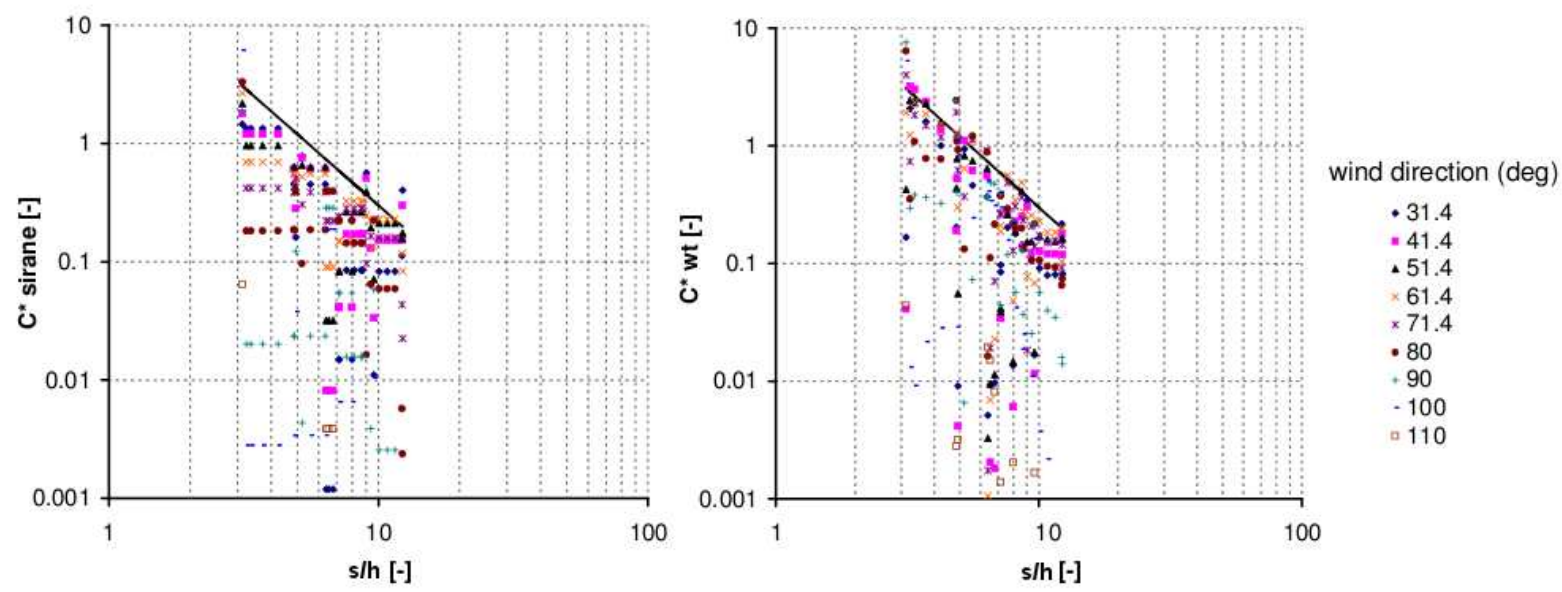

Figure 9: Dimensionless concentrations from SIRANE (left) and wind tunnel (right) as a function of source-receptor separation, $s$, for the cases used to study the sensitivity to wind direction. The solid line represents Equation (8)

is demonstrated in Figure 9, where the estimate for the upper-bound concentration is included as:

$$
C^{*}=30\left(\frac{s}{h}\right)^{-2}
$$

where $C^{*}$ is the dimensionless concentration as defined in Section [5.1, $s$ is the straight line separation between a source and a receptor and $h$ the mean building height. Inversesquare decay is apparent both for the SIRANE results (Figure 9- left) and the wind tunnel measurements (Figure 9 - right), with a constant of proportionality equal to 30 . This is lower than the constant quoted in Wood et al. (2009) because of the definition of $U_{h}$, here taken to be the speed at $z=h$ in the approach flow but the measured site roof-top wind speed in Wood et al. (2009). Barlow et al. (2009) show that the ratio of the local roof-top wind speed to that at $190 \mathrm{~m}$ on the BT Tower is 0.23 , to be compared with 0.59 for $U_{h} / U_{\text {ref }}$ in the approach flow in the wind tunnel.

As before, the first stage in the statistical comparison was graphical evaluation through scatter plots, presented in Figures 10 and 11. Figure 10, shows the complete set, whereas the data have also been classified according to the wind direction range in Figure 11 (left) for 'diagonal' winds and 11 (right) for 'normal' winds. We again use these terms rather loosely, the first comprising the wind directions $31.4^{\circ}, 41.4^{\circ}, 51.4^{\circ}$ and $61.4^{\circ}$, and the second $71.4^{\circ}, 80^{\circ}, 90^{\circ}, 100^{\circ}$ and $110^{\circ}$. Figure 11 shows that the correlation is better and the scatter less for diagonal than the normal cases. This confirms the findings from the preliminary analysis in Phase 1 (Section 5).

The final step in this analysis, that is the statistical evaluation, as described in Section 5, is reported in Table 5. SIRANE shows a general tendency to significantly underestimate $(\mathrm{FB}=0.75)$ wind tunnel observations for the 'normal' wind direction cases and slightly underestimate $(\mathrm{FB}=0.20)$ the observations for other angles. The better performance for diagonal wind directions was also seen in Phase 1, but there the tendency was to over-prediction. This apparent discrepancy can be explained by the fact that in the Phase 2 experiments there were a larger proportion of the receptors close to the source. The box model approach implies that the emission is distributed evenly within the street 


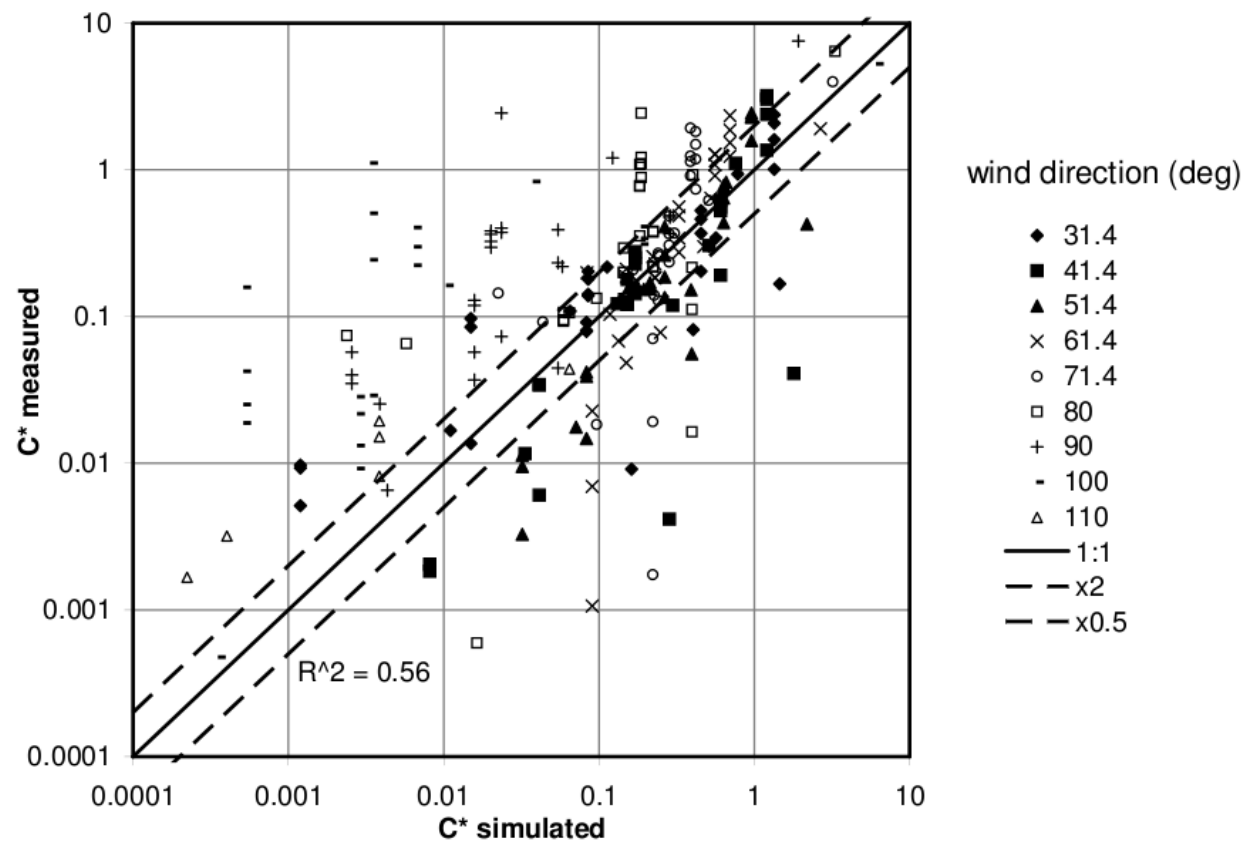

Figure 10: Scatter plot comparing the concentrations predicted by SIRANE with the wind tunnel data for the cases used to study the sensitivity to wind direction. 270 points
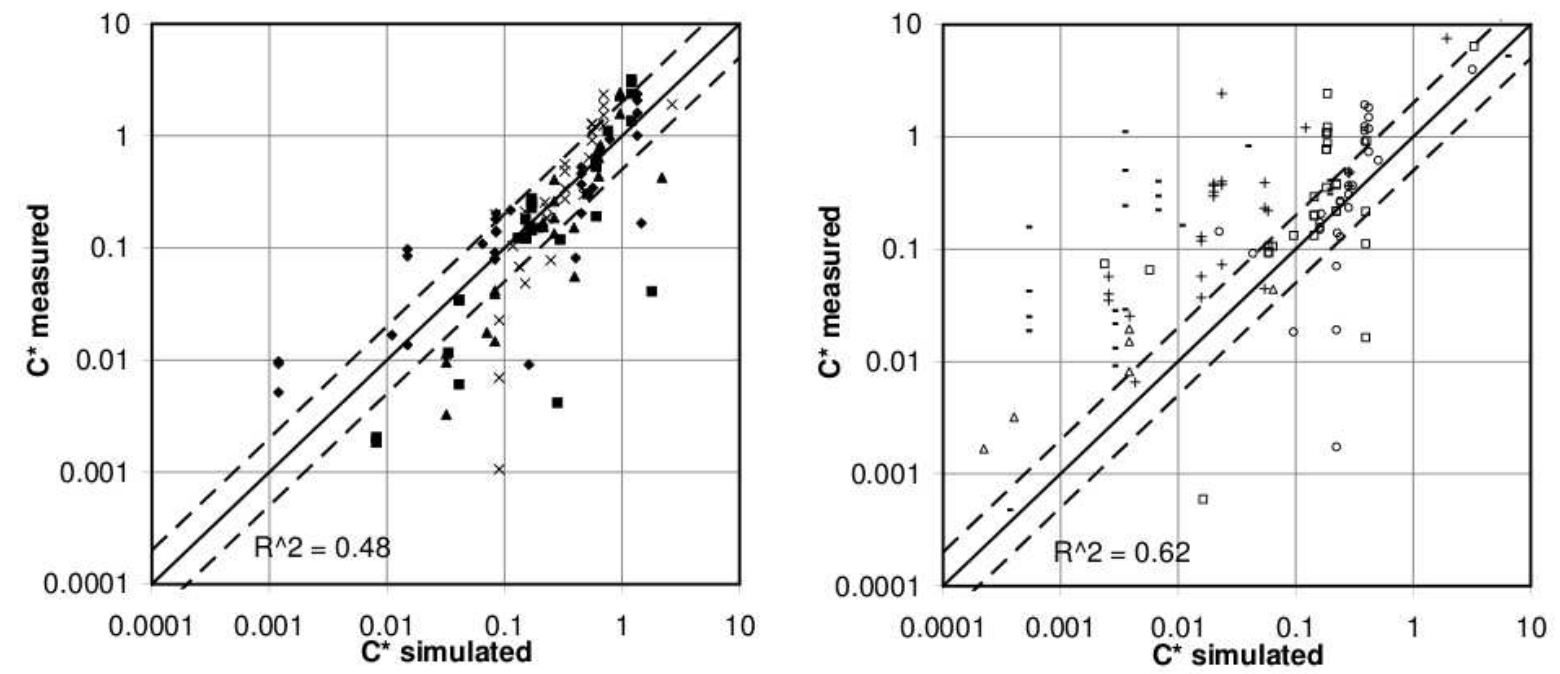

Figure 11: Scatter plot comparing the concentrations predicted by SIRANE with the wind tunnel data for the cases used to study the sensitivity to wind direction - left, 'diagonal' wind directions (120 points); right, 'normal' wind directions (150 points); legend as in Figure 10 
Table 5: Statistical evaluation of SIRANE predictions for the Phase 2 experiments for the cases used to study the sensitivity to wind direction. 270 points

\begin{tabular}{ccccc}
\hline Ideal target $->$ & 0 & 0 & 1 & 1 \\
\hline 'Good' (Chang\&Hanna 2004) $->$ & abs $\leq 0.3$ & $\leq 4$ & - & $\geq 0.5$ \\
\hline Data set & FB & NMSE & R & FAC2 \\
\hline wdir 110 & 0.29 & 3.18 & 0.87 & 0.17 \\
wdir 100 & 0.42 & 1.43 & 0.93 & 0.13 \\
wdir 90 & 1.31 & 21.76 & 0.90 & 0.17 \\
wdir 80 & 0.79 & 3.70 & 0.87 & 0.50 \\
wdir 71.4 & 0.53 & 1.28 & 0.82 & 0.53 \\
wdir 61.4 & 0.37 & 1.01 & 0.69 & 0.63 \\
wdir 51.4 & 0.16 & 1.54 & 0.58 & 0.57 \\
wdir 41.4 & 0.19 & 1.95 & 0.66 & 0.60 \\
wdir 31.4 & 0.02 & 0.85 & 0.78 & 0.60 \\
\hline All cases & 0.45 & 2.90 & 0.75 & 0.43 \\
'Diagonal' wdir & 0.20 & 1.37 & 0.69 & 0.60 \\
'Normal' wdir & 0.75 & 5.64 & 0.79 & 0.30 \\
\hline
\end{tabular}

containing the source and this inevitably leads to underestimation of concentrations close to the source. The overall performance, however, can be considered as 'good', according the Chang and Hanna (2004) criteria, for the diagonal wind direction cases. The normalized mean square error (NMSE) is acceptable for all but one of the cases studied, that being $90^{\circ}$. Results in this case are influenced by many low predicted values and some large observed ones. The correlation coefficient is 0.75 overall, due to the dominant influence of the decrease in concentrations with distance from the source, and is actually better for the 'normal' wind directions.

This underestimation of concentrations when the wind blows parallel to one set of streets (and, obviously, perpendicular to the other set) has already been observed in previous studies with regular arrays of buildings (Garbero, 2008). Wind tunnel studies (Garbero et al., 2010) showed that concentration gradients along the lateral streets (the ones perpendicular to the external flow) were very large in these cases. This variability cannot be adequately reproduced by SIRANE, which assigns a constant concentration within a single street segment. Of course, any segment may be sub-divided into a number of smaller segments to improve resolution in cases with large gradients. However, previous work (Garbero, 2008) has identified the problem to be the underestimation of lateral exchange in these situations, probably because the contribution from small-scale fluctuations produced by local instabilities in the flow at intersections is inadequately represented in SIRANE.

\subsection{Response to source location changes}

Simulations with a fixed wind direction but a number of source positions were carried out for a wind direction of $45^{\circ}$. The experimental database included tests with 7 different source positions and the total number of measurement points was slightly greater than 


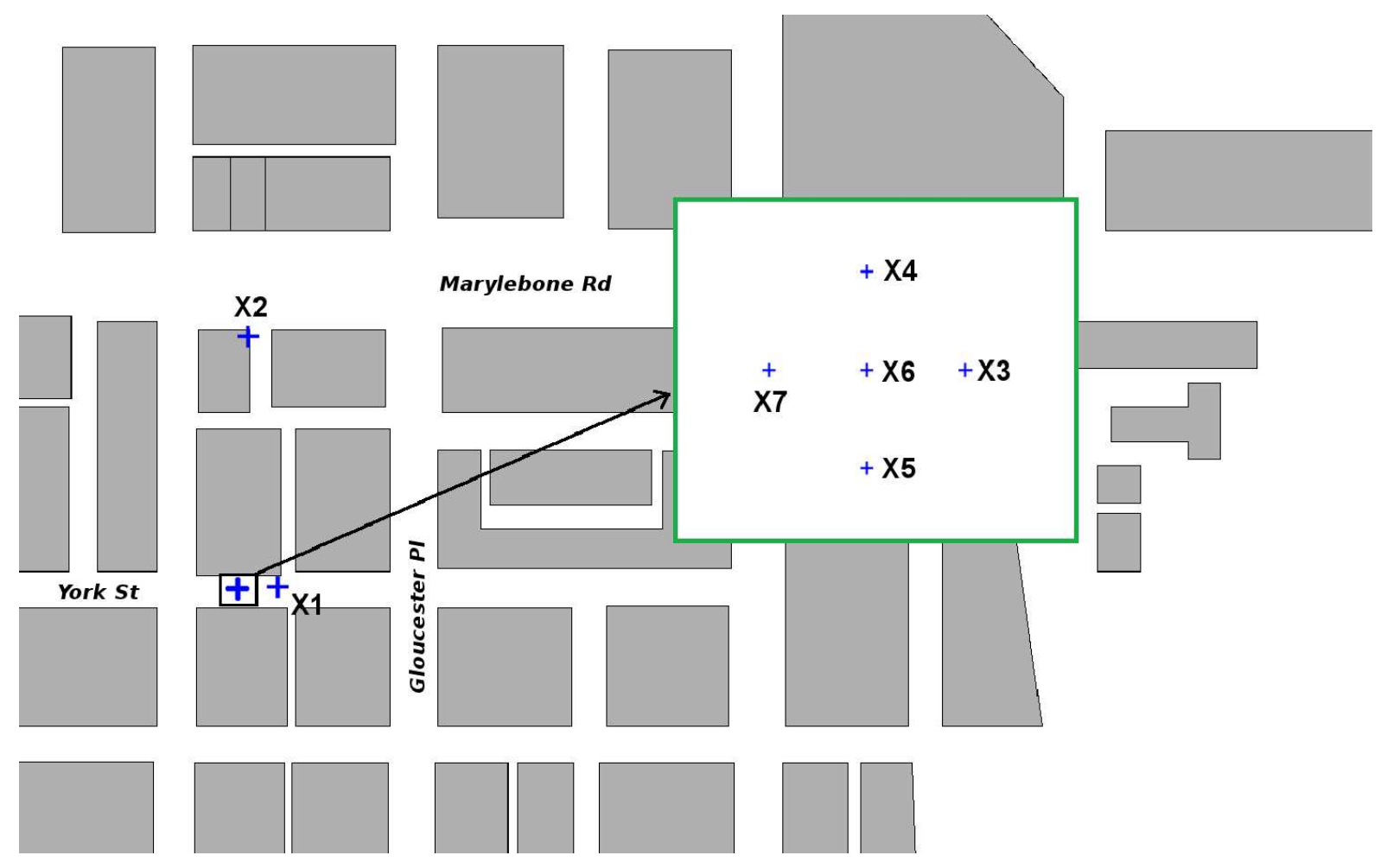

Figure 12: Map of the source positions used for the $45^{\circ}$ test cases; note that 5 of the 7 sources are actually very close to each other

4000. The location of the sources is shown in Figure 12, ' $\mathrm{X} 1$ ' is close to 'S1' (see Figure 3); ' $\mathrm{X} 2$ ' is in the same location as 'R1' (roof level, Figure 3); ' $\mathrm{X} 3$ ' to 'X7' are within York Street, upwind of 'X1', and separated only by few tens of centimetres (in full scale).

As in the previous case, both the measurements and predictions demonstrated the inverse-square decay behaviour, equation 8 , of the maximum ground level concentration with separation form the source. The statistical analysis of model performance, as described in the previous sections, resulted in:

$\mathrm{FB}=0.3, \mathrm{NMSE}=4.5, \mathrm{R}=0.37, \mathrm{FAC} 2=0.55$.

These results are on the boundary of the Chang and Hanna criteria for a 'good' model. One reason for this is very clearly shown by the scatter plot, Figure 13. SIRANE, being a form of a box model, does not show any sensitivity to the position of a source or a receptor within a given street segment, whereas the wind tunnel data show that this can be substantial in some cases. This explains the vertical clustering seen in the scatter plot.

\subsection{Response to changes in urban geometry}

In this final part of the paper we evaluate the response of SIRANE in simulating the blocking of several streets in the studied district. A series of wind tunnel experiments was carried out to investigate the impact of blockages (such as large trees, buses, etc.) on flow and dispersion behaviour. The wind tunnel work concentrated on fully blocked streets as the extreme, limiting case. Experiments were performed for a wind direction of $45^{\circ}$. These included a reference test with no blockages installed, referred to as case 


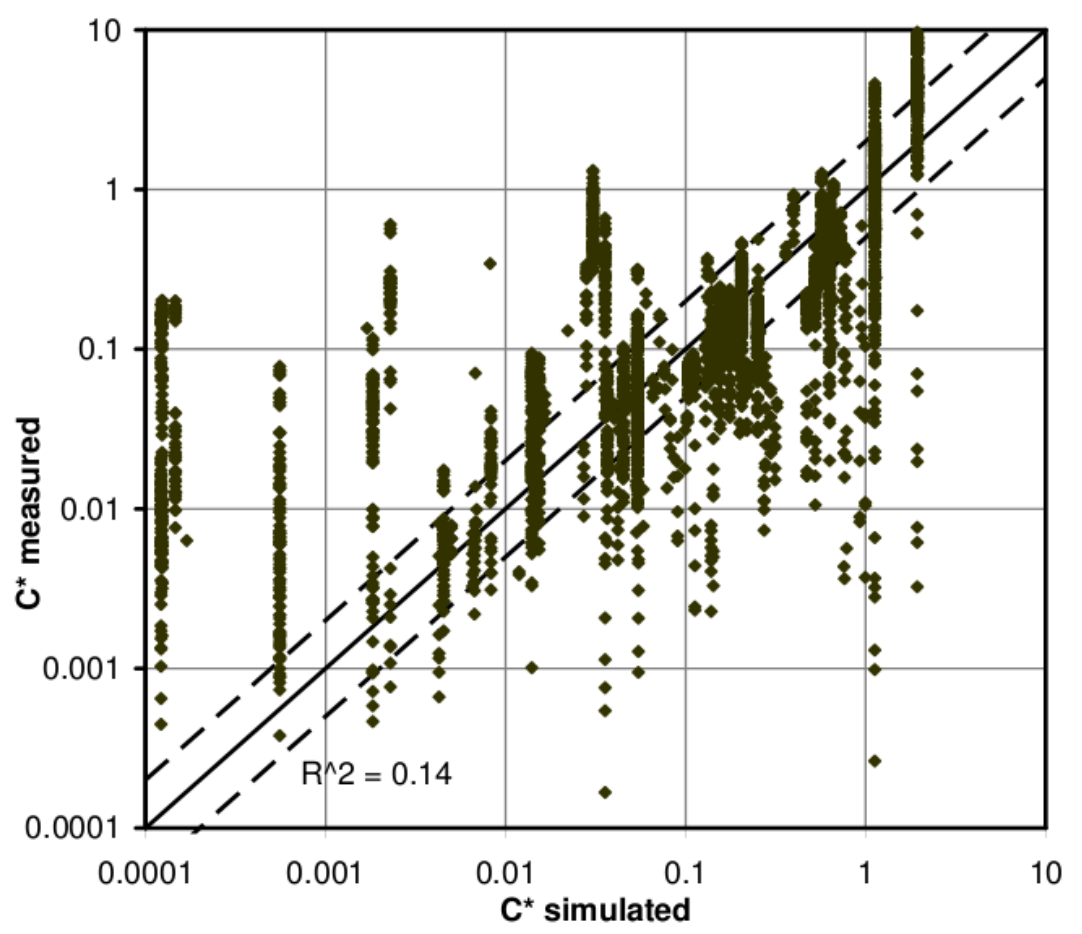

Figure 13: Scatter plot comparing the concentrations predicted by SIRANE with the wind tunnel data for the cases used to study the sensitivity to source position; wind direction $45^{\circ}, 4132$ points

'a'. Seven different street blockages were tested (cases 'b' to 'h'). The arrangement of the source, receptors and street blockages is shown in Figure 14.

Results of the reference case 'a' are given in Figure 15-right, while the corresponding arrangement of the street network in SIRANE is shown in Figure 15-left. The model performance for this case, in terms of the statistical indices presented in Section 5.1, is very good, according Chang and Hanna (2004) criteria (see Table 6).

The model SIRANE, in its present version, does not allow a zero pollutant flux to be imposed at the beginning or the end of one of the streets connected to an intersection. Therefore, in order to simulate the modified (blocked) street network we had to change the position of the end nodes of the streets that were blocked, thus removing the link with the correspondent intersection. These new end nodes are linked directly to the external atmosphere, just as happens with a street bordered by buildings that ends in an open space without any pollutant sources in it (for example a park). It is worth mentioning that, in SIRANE, it is possible to displace a node without altering the street dimensions (width, length and height) that have been computed on the geometry of the base scenario.

Firstly we analyse case 'f', where the street nr. 78 (Figure 16-left) has been blocked. In order to impose a zero flux of pollutant at the intersection we need to disconnect street 78 from the intersection formed by streets 79,77 and 76 . The resulting concentration field at roof level (Figure 16-right) shows the strong effect of the blockage in the pollutant distribution within the street network as simulated by SIRANE. The pollutant flux from street 79 is no longer diluted with clean air coming from street 78 and is now distributed differently within the downwind streets in comparison with the reference case. This 


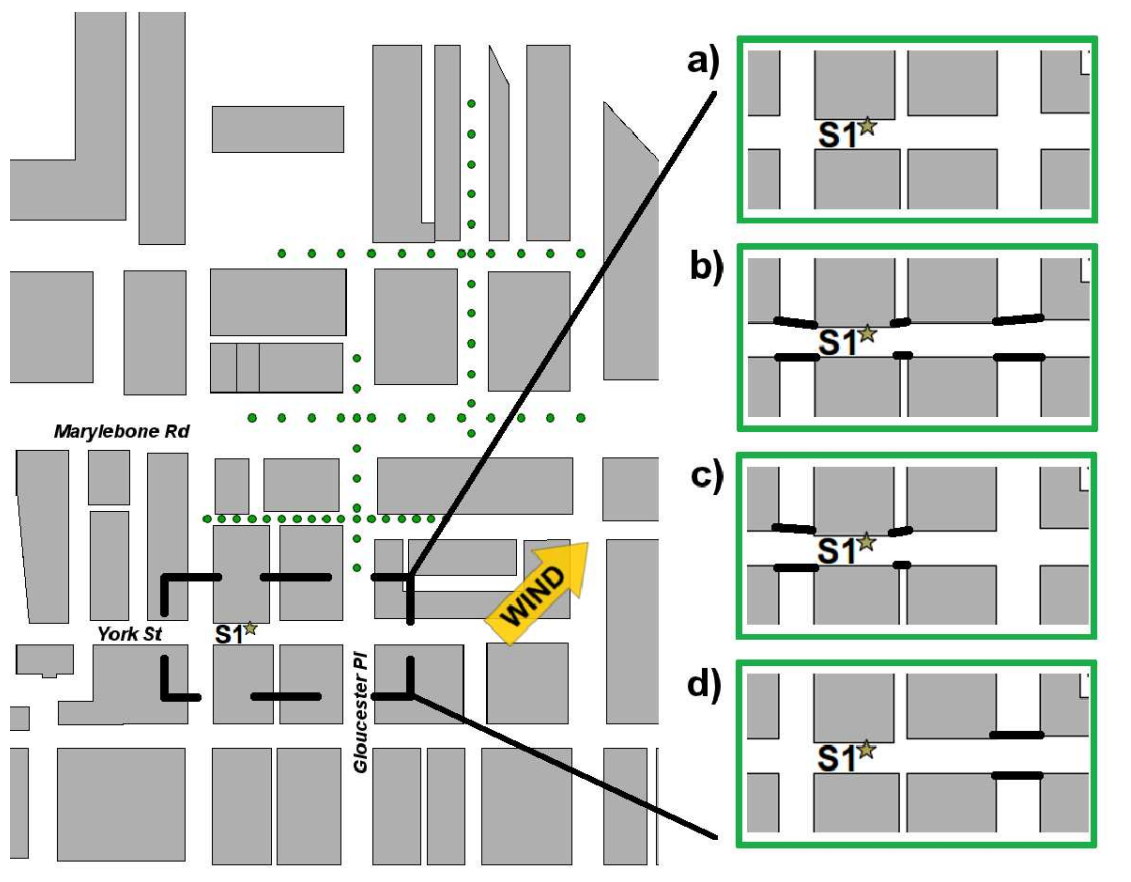

e)

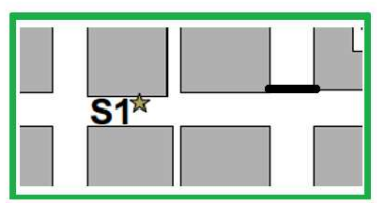

f)

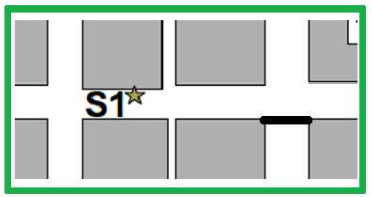

g)

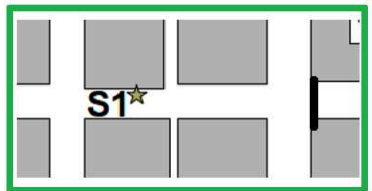

h)

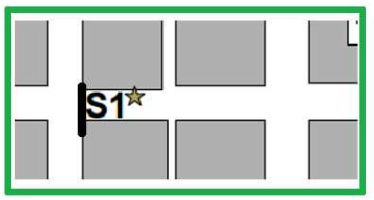

Figure 14: Source location (S1) and receptor positions (dots) for the modify geometry dataset; the blocked streets in the 8 studied cases (a to h) are shown on the right hand side of the figure

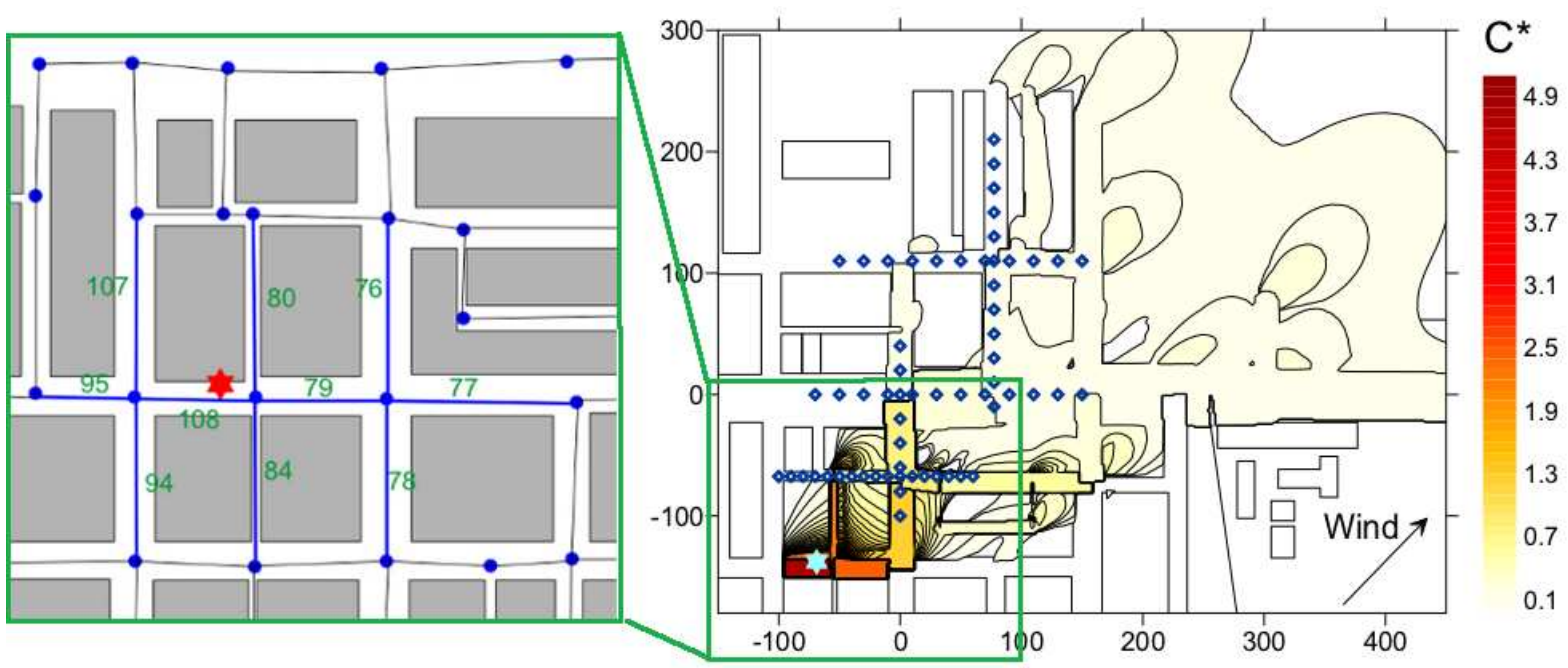

Figure 15: Reference case (unblocked geometry, case 'a'); left: detailed street network geometry used in SIRANE, values shown are the street IDs; right: map of calculated non-dimensional surface concentrations 
Table 6: Statistical evaluation of SIRANE predictions for the Phase 2 experiments for the cases used to study the changes in urban geometry. 472 points (excluding $1^{\text {st }}$ attempt)

\begin{tabular}{ccccc}
\hline Ideal target $->$ & 0 & 0 & 1 & 1 \\
\hline 'Good' (Chang\&Hanna 2004) $->$ & abs $\leq 0.3$ & $\leq 4$ & - & $\geq 0.5$ \\
\hline Data set & FB & NMSE & R & FAC2 \\
\hline Case 'a' & 0.13 & 1.16 & 0.84 & 0.67 \\
Case 'b' 1'st attempt & -1.65 & 23.90 & 0.49 & 0.08 \\
Case 'b' & -0.62 & 2.21 & 0.39 & 0.28 \\
Case 'c' & 0.23 & 2.68 & 0.66 & 0.48 \\
Case 'd' & -0.54 & 1.95 & 0.65 & 0.42 \\
Case 'e' & 0.82 & 4.00 & 0.85 & 0.57 \\
Case 'f' & -0.14 & 1.18 & 0.64 & 0.68 \\
Case 'g' & 0.11 & 0.84 & 0.73 & 0.62 \\
Case 'h' & -0.40 & 1.41 & 0.64 & 0.65 \\
\hline All cases 'b'- $\mathrm{h}$ & 0.05 & 2.28 & 0.63 & 0.53 \\
\hline
\end{tabular}

results in significantly higher concentrations in street 77 and slightly lower concentrations in street 76, and in greater plume spread over the whole district. Comparing the results with the wind tunnel measurements (see Table 6), the model shows a tendency to slightly overestimate the ground level concentrations (negative FB), though the indices meet all three quality criteria.

As a second example, we analyse case ' $b$ ', in which six different streets have been blocked (Figure 17-left). The simulations, in this case, turned out to be more complex. The presence of the barriers along the street where the source is placed implies no exchanges with the surrounding streets of the intersections. Furthermore, in the streets 107, 80 and 76, the only inflow of pollutant will be that at roof level (and eventually that at the downwind intersection). A first attempt to simulate this was done by creating two new nodes for each intersection that had been blocked, using the same procedure adopted above for case ' $\mathrm{f}$ '. These nodes are positioned close to the pre-existing nodes but are not connected to them (Figure 17-left).

The simulated concentration distribution is presented in Figure 17-right. As expected, the pollutant concentration increase significantly along the street where the source is located, because the exchanges with the surrounding streets at the intersections are now inhibited. However, the concentration map shows two unexpected consequences of the new nodes of streets 107, 80 and 76: the first is the increase of pollutant concentration in streets 80 and 76 to which direct advection has been blocked; the second is two regions of very low concentration originating from two of the three modified intersections.

The high concentrations in streets 80 and 76 can be explained by the position of the new nodes. As mentioned earlier, these nodes are disconnected from the intersections and directly linked to the external atmosphere where the pollutant concentration $C_{\text {ext }}$ is high due to the vertical transfer from streets 108 and 79 into the overlying flow. Therefore there will be an inflow of pollutant through these new nodes, which is seen as a mean 


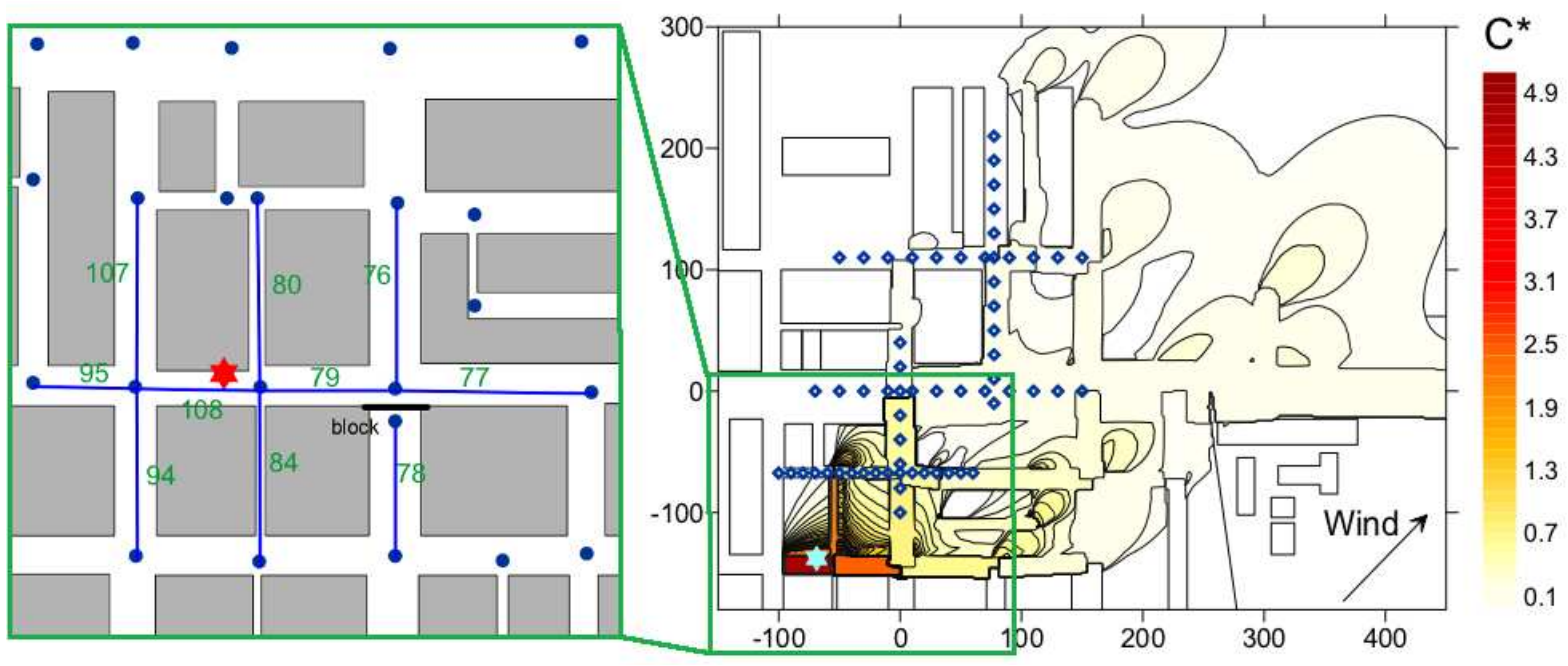

Figure 16: Case 'f' (blocked Gloucester Pl. at York St., south side); left: detailed street network geometry used in SIRANE, values shown are the street IDs; right: map of calculated non-dimensional surface (either ground or roof) concentrations

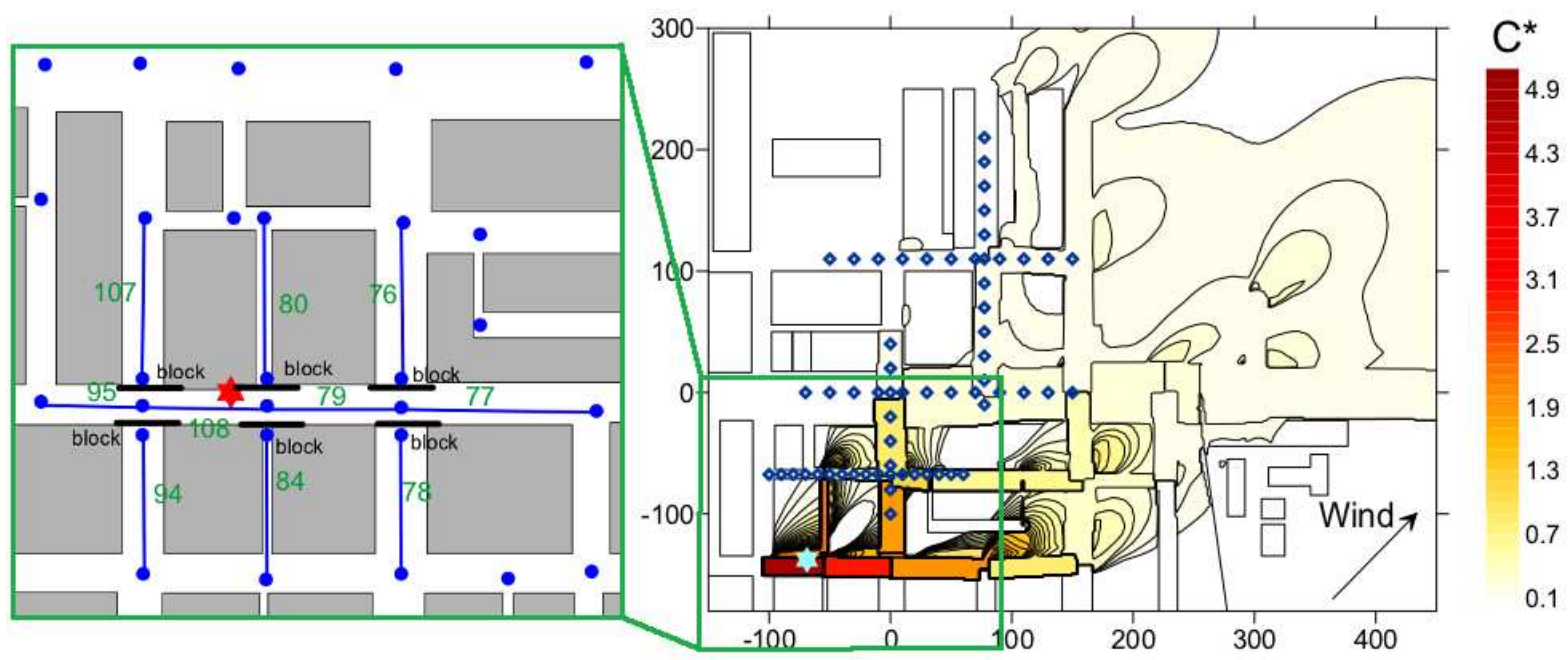

Figure 17: Case 'b', first attempt (blocked Upper Montagu St., Thornton Pl. and Gloucester Pl. at York St., both sides); left: detailed street network geometry used in SIRANE, values shown are the street IDs; right: map of calculated non-dimensional surface concentrations 
advective flux directed along the street axes, computed as:

$$
W H U_{\text {street }} C_{\text {ext }}
$$

where $W$ and $H$ denote the street width and height, respectively and $U_{\text {street }}$ is the mean advective velocity within the street and along its axis. These fluxes are much larger than the turbulent fluxes at roof level since the vertical exchange velocity between the street and atmosphere, referred here as $u_{d}$ (eq.2), is expected to be approximately one order of magnitude lower than $U_{\text {street }}$. The presence of these fluxes results in an overestimation of pollutant concentration in streets 107,80 and 76 that clearly leads to poor model performances (Table [6). These undesired high pollutant fluxes, entering streets 80 and 76 , are also the cause of the low concentration plumes evident in Figure 17-right. These are generated by negative pollutant sources located at roof level and created automatically by SIRANE in order to preserve the mass balance between the fluxes entering and leaving these streets. It should be emphasised that these features derive from the particular way in which SIRANE has been compiled, rather than being generic features of street network models.

In order to simulate the desired zero flux of pollutant at the intersection we had then to displace the new nodes upwind of the blocked intersections (see Figure 18-left), where the pollutant concentrations are zero. In this way the pollutant advective flux entering the street through this node is zero and the only non-zero pollutant flux entering the streets is that coming from the external flow at roof level, as actually happens in the wind tunnel experiments. Note that the fact that street 107 crosses streets 95 and 108 does not imply that they are connected to each other because they are not linked to the same node, where pollutant exchanges within the urban canopy take place in the model. The concentration map is given in Figure 18-right. The corresponding statistics in Table 6] clearly show that the model performance has been significantly improved compared to the previous attempt.

Finally we focus on the overall statistical comparison between the wind tunnel results and SIRANE calculations, using all 472 data points. The performance indices are listed in Table [6] and the scatter plot shown in Figure 19. Model performance is good and meets all three quality indicators. Furthermore, the results show the ability of the model implemented in SIRANE in simulating short-range pollutant transfer mechanisms within the urban canopy - namely the advective fluxes along the street axes, the turbulent fluxes at the street intersection and the vertical pollutant exchanges at roof level.

\section{Conclusions}

The aim of this study was to compare dispersion calculations using the SIRANE model with detailed results from wind tunnel experiments in order to examine model performance in simulating short-range pollutant dispersion in urban areas. The wind tunnel experiments were carried as part of the DAPPLE project using a 1:200 scaled model of the DAPPLE field site in central London. The model evaluation work was conducted in two phases: Phase 1, reproducing the conditions of field trials conducted in 2003 and 2004, was used for preliminary analysis of model performance; Phase 2 included an extensive database of experimental results, suitable for a significant statistical analysis in 


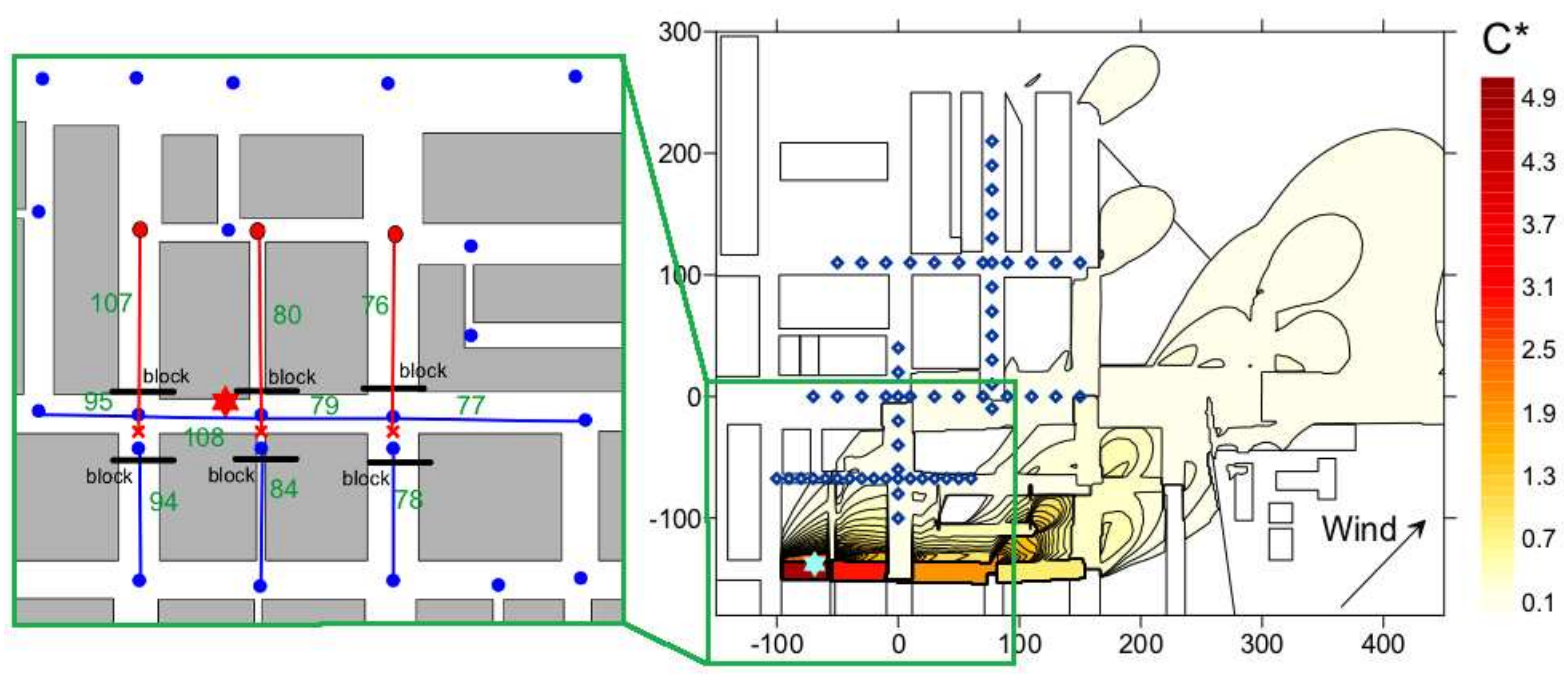

Figure 18: Case 'b', final attempt (blocked Upper Montagu St., Thornton Pl. and Gloucester Pl. at York St., both sides); left: detailed street network geometry used in SIRANE, values shown are the street IDs; right: map of calculated non-dimensional surface concentrations

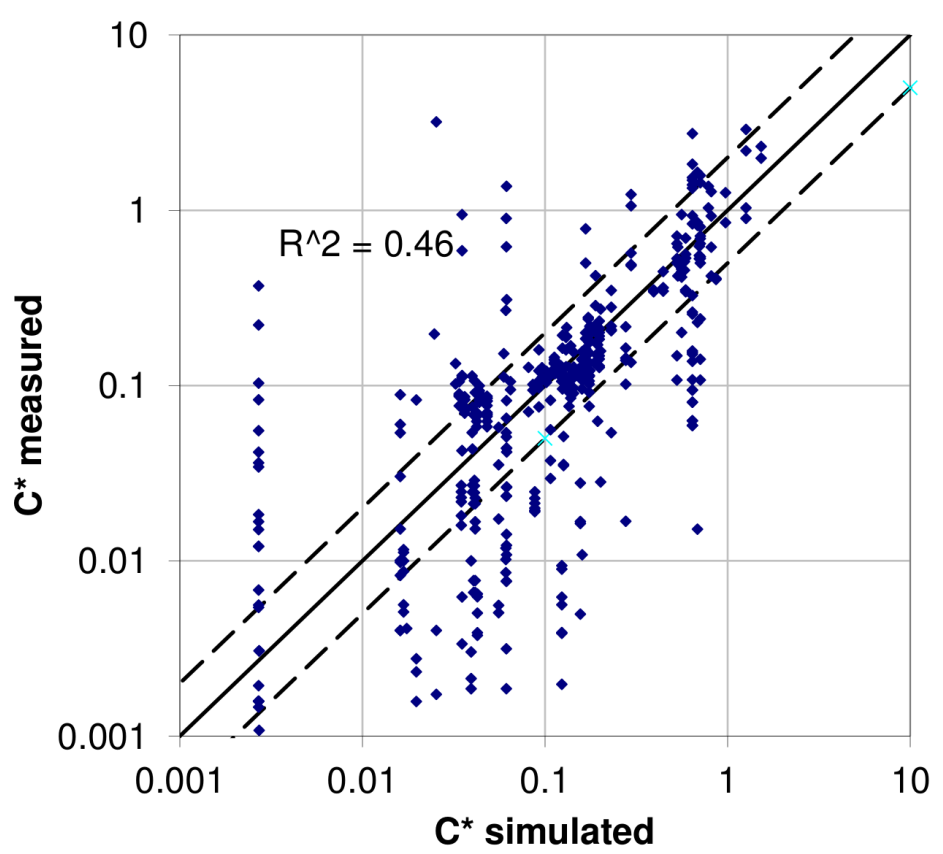

Figure 19: Scatter plot comparing the concentrations predicted by SIRANE with the wind tunnel data for the cases used to study the changes in urban geometry. 472 points 
a systematic study. Both datasets were large and contrasting the outcomes of the two phases illustrates how formal evaluation can be biased by the choice of data.

The preliminary analysis was performed with a dataset characterised by different tests with a variety of source positions, receptor locations and wind directions. This preliminary study was complemented by a sensitivity analysis which focused on three varying input parameters: the plume spread parameterisation, site aerodynamic parameters and the wind direction. Sensitivity to wind direction was shown to be by far the most significant. Modest changes in the other two input parameters had very little effect on model performance.

Phase 2 was then conducted by varying more systematically the simulation and experimental scenarios. Wind direction was the first focus, picking-up on the conclusions from Phase 1. Wind tunnel experiments and simulations were performed with a fixed set of receptor and source positions, for wind directions between $110^{\circ}$ and $31.4^{\circ}$. The results showed that the correlation between experimental and numerical results was better in the case of wind directions diagonal to the streets axes, while for wind directions nearly parallel to the streets (within, say, $\pm 20^{\circ}$ ) the model was, in general, less accurate. This result is in line with previous validation studies (Garbero, 2008) and is probably due to the high variability of concentrations in lateral streets when the wind is aligned with a rectangular, or nearly so, street geometry (Garbero et al., 2010).

The next objective was to assess how source position affected the general performance of the model but with a fixed wind direction so that this critical parameter was removed from the analysis. Wind tunnel results show how the concentration field responds to relatively small changes in source position. SIRANE, being a box model, cannot reproduce this sensitivity if the source remains within a given street segment. Similarly, the model cannot predict the variation of concentration within a street segment; i.e. it is insensitive to receptor position within a street segment. The aim was to quantify, in terms of model performance, the consequences of these deficiencies. Model performance met two of the performance criteria proposed by Chang and Hanna (2004) but the normalised mean square error was greater than the target value, reflecting the issues summarised above.

A final test examined the response to changes in the street geometry, achieved in the wind tunnel by fully blocking selected streets with a simple barrier and in SIRANE by removing the appropriate link. This changed the balance between advection of plume material along the streets and in the boundary layer above roof level.

The overall model performance, measured using the Chang and Hanna (2004) criteria can be considered as 'good'. The model, however, showed a general tendency to overestimate the wind tunnel observations when the receptors were relatively distant from the source, whilst under-estimating concentrations at receptors closer to the emission, especially when the source was within the canopy (modelled as a "street source" by SIRANE). Detailed analysis of the results showed that ground level sources were better represented by the model than roof level sources. Performance was generally good for wind directions that were very approximately diagonal to the street axes, while cases with wind directions almost parallel (within $20^{\circ}$ ) to street axes gave results with larger uncertainties (failing to meet the quality targets).

The methodology used in this evaluation exercise, relying on systematic wind tunnel studies on a scaled model of a real neighbourhood, proved very useful for assess- 
ing strengths and weaknesses of the SIRANE model, complementing previous validation studies performed with either on-site measurements (Soulhac et al., 2003) or wind tunnel measurements over idealised urban geometries (Garbero, 2008). Clearly, performance when the wind is nearly aligned with the street system is a concern that needs to be addressed. Developing rules for sub-dividing street segments, currently defined as the section between intersections, where large gradients are expected is an obvious first step. However, it is probably true that performance will always be less satisfactory for these wind directions where, in reality, quite small detail of the geometry can become important, as demonstrated by Robins et al. (2002).

No one study, even one as detailed as that presented here, fully defines how well a model performs. This is realised through the combined results of many evaluation studies, using wind tunnel and field data. Experiments with point sources are particularly useful in this as they can pinpoint strengths and weaknesses more readily. However, such experiments are hardly ever designed to give an unbiased dataset, reinforcing the need for a large number of independent evaluations of performance. For instance, as we report in Section 6.1, the location of receptors can play a major role in determining whether SIRANE is seen to over or under-predict. Even though quite large numbers of receptors were used in some of the test cases, many more, more evenly spread throughout the study area and not just at ground level, would have provided a more comprehensive and unbiased picture of model performance - but the 'cost' would have been prohibitive. The option of conducting just one or two extremely detailed experiments can also introduce considerable bias without the important benefit of addressing the sensitivity of model performance to changes in boundary conditions and other physical factors.

\section{References}

Allwine, K.J., Shinn, J.H., Streit, G.E., Clawson, K.L., Brown, M., 2002. Overview of URBAN 2000: A multiscale field study of dispersion through an urban environment. Bull. Am. Meteorol. Soc. 83, 521-536.

Arnold, S.J,, ApSimon, H., Barlow, J., Belcher, S., Bell, M., Boddy, J.W., Britter, R., Cheng, H., Clark, R., Colvile, R.N., Dimitroulopoulou, S., Dobre, A., Greally, B., Kaur, S., Knights, A., Lawton, T., Makepeace, A., Martin, D., Neophytou, M., Neville, S., Nieuwenhuijsen, M., Nickless, G., Price, C., Robins, A., Shallcross, D., Simmonds, P., Smalley, R.J., Tate, J., Tomlin, A.S., Wang, H., Walsh, P., 2004. Introduction to the DAPPLE air pollution project. Sci. Total. Environ. 332, 139-153.

Ball, A., Hill, R., Jenkinson, P., 2008. Integration of air quality modelling and monitoring methods: review and applications. U. K. Environment Agency, Science Report SC060037/SR1, http://publications.environmentagency.gov.uk/epages/eapublications.storefront.

Barlow, J.F., Dobre, A., Smalley, R.J., Arnold, S. J., Tomlin, A.S., Belcher, S.E., 2009. Referencing of street-level flows: results from the DAPPLE 2004 campaign in London, UK. Atmos. Environ. 43, 5536-5544. 
Belcher, S. E., 2005. Mixing and transport in urban areas. Philos. Trans. R. Soc. London, Ser. A 363, 2947-2968.

Berkowicz, R., 2000. OSPM - A Parameterised Street Pollution Model. Environ. Monit. Assess. 65, 323-331.

Blocken, B., Gualtieri, C., 2012. Ten iterative steps for model development and evaluation applied to Computational Fluid Dynamics for Environmental Fluid Mechanics. Environ. Modell. Softw. 33, 1-22.

Briggs, G.A., 1973. Diffusion estimation for small emissions. In: ATDL Contribution File No. 79, Air Resources Atmospheric Turbulence and Diffusion Laboratory, NOAA, Oak Ridge, Tennessee.

Britter, R. E., Hanna, S. R., 2003. Flow and dispersion in urban areas. Ann. Rev. Fluid Mech. 35, 469-496.

Brook, D. R., Felton, N. V., Clem, C. M., Strickland, D. C. H., Griffiths, I. H., Kingdon, R. D., 2003. Validation of the Urban Dispersion Model (UDM). Int. J. Environ. Pollut. $20,11-21$.

Carpentieri, M., Robins, A.G., 2010. Tracer flux balance at an urban canyon intersection. Boundary-Layer Meteorol. 135, 229-242.

Carpentieri, M., Robins, A.G., Baldi, S., 2009. Three-dimensional mapping of air flow at an urban canyon intersection. Boundary-Layer Meteorol. 133, 277-296.

CERC, 2001. ADMS-Urban User guide. Cambridge Environmental Research Consultants.

Chang, J.C., Hanna, S.R., 2004. Air quality model performance evaluation. Meteorol. Atmos. Phys. 87, 167-196.

Di Sabatino, S., Solazzo, E., Paradisi, P., Britter, R., 2008. A simple model for spatiallyaveraged wind profiles within and above an urban canopy. Boundary-Layer Meteorol. 127, 131-151.

Garbero, V., 2008. Pollutant dispersion in urban canopy study of the plume behaviour through an obstacle array. PhD thesis, École Centrale de Lyon, France.

Garbero, V., Salizzoni, P., Soulhac, L., 2010. Experimental study of pollutant dispersion within a network of streets. Boundary-Layer Meteorol. 136, 457-487.

Hall, D.J, Spanton, A.M., Griffiths, I.H., Hargrave, M., Walker, S., John, C., 2001. The UDM: A puff model for estimating dispersion in urban areas. $7^{\text {th }}$ International Conference on Harmonisation within Atmospheric Dispersion Modelling for Regulatory Purposes, 28 - 31 May, 2001, Belgirate, Italy, pp. 256-260.

Hamlyn, D., Hilderman, T., Britter, R., 2007. A simple network approach to modelling dispersion among large groups of obstacles. Atmos. Environ. 41, 5848-5862. 
Hanna, S.R., Britter, R., Franzese P., 2003. A baseline urban dispersion model evaluated with Salt Lake City and Los Angeles tracer data. Atmos. Environ. 37, 5069-5082.

Hunt, J.C.R., Britter, R.E., Carruthers, D.J., Daish, N.C., 2004. Dispersion from accidental releases in urban areas UK Atmospheric Dispersion Modelling Liaison Committee, Report No. ADMLC/2002/3

Irwin, H.P.A.H., 1981. The design of spires for wind simulation. J. Wind Eng. Ind. Aerodyn. 7, 361-366.

Jakeman, A.J., Letcher, R.A., Norton, J.P., 2006. Ten iterative steps in development and evaluation of environmental models. Environ. Modell. Softw. 21, 602-614.

Kukkonen, J., Partanen, L., Karppinen, A., Walden, J., Kartastenpää, R., Aarnio, P., Koskentalo, T., Berkowicz, R., 2003. Evaluation of the OSPM model combined with an urban background model against the data measured in 1997 in Runeberg Street, Helsinki. Atmos. Environ. 37, 1101-1112.

MacDonald, R.W., Griffiths, R.F., Hall, D.J., 1998. An improved method for the estimation of surface roughness of obstacle arrays. Atmos. Environ. 32, 1857-1864.

Oke, T. R., 1987. Boundary layer climates. Routledge, London.

Pasquill, F., Smith, F.B., 1983. Atmospheric diffusion. John Wiley \& Sons, New York.

Robins, A.G., Savory, E., Scaperdas, A., Grigoriadis, D., 2002. Variability and sourcereceptor relations at a street intersection. Water Air Soil Pollut. Focus 2, 381-393.

Salizzoni, P., Soulhac, L., Mejean, P., 2009a. Street canyon ventilation and atmospheric turbulence. Atmos. Environ. 43, 5056-5067.

Salizzoni, P., Van Liefferinge, R., Mejean, P., Soulhac, L., Perkins, R.J., 2009b. Influence of wall roughness on the dispersion of a passive scalar in a turbulent boundary layer. Atmos. Environ. 43, 734-748.

Scaperdas, A., Colvile, R. N., 1999. Assessing the representativeness of monitoring data from an urban intersection site in central London, UK. Atmos. Environ. 33, 661-674.

Snyder, W.H., 1981. Guideline for fluid modeling of atmospheric diffusion. U. S. Environmental Protection Agency, Report EPA-600/8-81-009.

Soulhac, L., Garbero, V., Salizzoni, P., Mejean, P., Perkins, R.J., 2009. Flow and dispersion in street intersections. Atmos. Environ. 43, 2981-2996.

Soulhac, L., Perkins, R.J., Salizzoni, P., 2008. Flow in a street canyon for any external wind direction. Boundary-Layer Meteorol. 126, 365-388.

Soulhac, L., Puel, C., Duclaux, O., Perkins, R.J., 2003. Simulations of atmospheric pollution in Greater Lyon an example of the use of nested models. Atmos. Environ. $37,5147-5156$. 
Soulhac, L., Salizzoni, P., Mejean, P., Didier, D., Rios, I., 2012. The model SIRANE for atmospheric urban pollutant dispersion; Part II, validation of the model on a real case study. Atmos. Environ. 49, 320-337.

Soulhac, L., Salizzoni, P., Perkins, R.J., 2011. The model SIRANE for atmospheric urban pollutant dispersion; Part I, presentation of the model. Atmos. Environ. 45, 7379-7395.

Vardoulakis, S., Fisher, B.E.A., Pericleous, K., Gonzalez-Flesca, N., 2003. Modelling air quality in street canyons: a review. Atmos. Environ. 37, 155-182.

Venkatram, A., 1992. Vertical dispersion of ground level releases in the surface boundary layer. Atmos. Environ. 26, 947-949.

Weil, J.C., 1985. Updating applied diffusion models. J. Climate Appl. Meteorol. 24, $1111-1130$.

Wood, C.R., Arnold, S.J., Balogun, A.A., Barlow, J.F., Belcher, S., Britter, R.E., Cheng, H., Dobre, A., Lingard, J.J.N., Martin, D., Neophytou, M.K., Petersson, F.K., Robins, A.G., Shallcross, D.E., Smalley, R.J., Tate, J.E., Tomlin, A.S., White, I.R., 2009. Dispersion experiments in Central London: the 2007 DAPPLE project. Bull. Am. Meteorol. Soc. 90, 955-969. 